\title{
Flax fiber and its composites: An overview of water and moisture absorption impact on their performance
}

\author{
Abdul Moudood ${ }^{1}$, Anisur Rahman ${ }^{1}$, Andreas Öchsner $^{2}$, Mainul Islam ${ }^{3}$, Gaston Francucci ${ }^{4}$ \\ ${ }^{1}$ Griffith School of Engineering, Gold Coast Campus, Griffith University, Queensland 4222, \\ Australia \\ ${ }^{2}$ Esslingen University of Applied Sciences, Faculty of Mechanical Engineering, Kanalstrasse 33, \\ 73728 Esslingen, Germany \\ ${ }^{3}$ School of Mechanical \& Electrical Engineering, University of Southern Queensland, West Street, \\ Toowoomba, QLD 4350, Australia \\ ${ }^{4}$ Research Institute of Material Science and Technology (INTEMA-CONICET), National University \\ of Mar del Plata, J. B. Justo 4302, B7608FDQ, Mar del Plata, Argentina
}

Corresponding author: Gaston Francucci, e-mail: gastonfrancucci@gmail.com

Tel: +5492236022676

\begin{abstract}
Contemporary researchers have specified that natural flax fiber is comparable with synthetic fibers due to its unique physical and mechanical characteristics which have been recognized for decades. Flax fiber reinforced composites have the potential for wide usage in sport and maritime industries, and as automotive accessories. In addition, this composite is in the development stages for future applications in the aeronautical industry. However, designing the flax composite parts is a challenging task due to the great variability in fiber properties. This is caused by many factors, including the plant origin and growth conditions, plant age, location in the stem, fibers extraction method, and the fact that there is often a non-uniform cross-section of the fibers. Furthermore, the water and moisture absorption tendency of the flax fibers and their composites and the consequent detrimental effects on their mechanical performance are also major drawbacks. Fibers may soften and swell with absorbed water molecules, which could affect the performance of this bio-composite. Flax fibers' moisture absorption propensity may lead to a deterioration of the fiber-matrix interface, weakening the interfacial strength and ultimately degrading the quality of the composite. This review represents a brief summary of the main findings of research into flax fiber reinforced composites, focusing on the challenges of its water and moisture absorption behavior on their performance.
\end{abstract}

Keywords: Flax fiber composites, Moisture absorption, Mechanical properties, Interfacial strength, Water diffusion

\section{Introduction}

Environmental awareness is a most important concern nowadays. Scientists all over the world are enthusiastic about the research of environmentally-friendly materials, owing to the increasing rate of greenhouse gas emissions and other related health hazards. The various products made from plastic and metal have a significant impact on the environment. Specifically, for composite materials, global awareness about the environmental impact of synthetic fibers throughout their manufacturing, usage, and end-life has greatly increased in recent years. In this context, natural fibers and their composites are considered to be one of the major 
alternatives and have occupied a substantial place in the field of material research during the last few decades. They are lightweight, inexpensive and structurally efficient materials that can replace the commonly used conventional synthetic fiber composites in some engineering applications. Thus, the production of eco-friendly and sustainable bio-based materials, with economic advantages, has resulted in increased attention in developing novel natural fiber reinforced composites.

Plant fibers, a sub-section of natural fibers, are cost-effective and offer good specific mechanical properties when compared to glass fibers. ${ }^{1,2}$ Monteiro et al. ${ }^{3}$ mentioned that economic, technical, societal and environmental benefits are achieved by using plant fibers instead of synthetic fibers for reinforcement. Summerscales et al. ${ }^{4}$ also reported that automobile accessories manufactured with plant fibers are light in weight. Due to this weight reduction, vehicles require less energy to operate. These fibers are extracted from different parts of the plant such as from the outer part of the plant stem, i.e., the bast (e.g., jute, kenaf, hemp, ramie, flax), leaf (e.g., sisal), fruit (e.g., coconut), and seed (e.g., cotton).

According to statistical data, the worldwide production rate of bast fibers is higher than the other types, and they are more popular among current fiber composite researchers. ${ }^{5,6}$ Further, flax is one of the most widely used natural fibers of the bast family for composite reinforcement. ${ }^{7}$ However, the chemical composition and microstructure of vegetable fibers permits moisture absorption from the environment, which causes weak bindings between the fiber and the polymer matrix. Like other vegetable fibers, the highly hydrophilic nature of flax fibers and the moisture sensitivity of their composites are the main disadvantages. ${ }^{8,9}$ Occasionally, due to the incompatibility between hydrophilic plant fibers and hydrophobic thermoplastic and thermoset matrices, physical and chemical treatments on such fibers and/or matrices are needed to increase the adhesion between them. ${ }^{2,7,10}$

In particular, the overall quality of the composites depends on the properties of the fibers, the matrix and their interface. Water and moisture absorption of plant fibers have multiple effects, in terms of their properties, morphology, chemical composition and dimensional stability. The composites made with fibers taken from different relative humidity $(\mathrm{RH})$ environments are expected to behave differently. On the other hand, when the composites are made with dry fibers, these can also absorb moisture in various conditions of humidity. Furthermore, if the composites are immersed under water, their properties are likely to be degraded by absorbing water. Therefore, the effect of $\mathrm{RH}$ and water or moisture absorption on the properties of flax fibers and their composites are the main points of interest of this review paper.

\section{Natural and synthetic fibers}

Natural fibers are very popular reinforcements used for manufacturing composites for a wide variety of engineering applications. These fibers are gradually occupying the place of synthetic fibers in some applications due to a sustainability viewpoint. The composites made with synthetic fibers, such as carbon or glass fibers, are known as high-performance composites. Several studies $^{11-13}$ reported about the recycling problems of the synthetic fiber composites and how environmental hazards were caused by these fibers. On the other hand, researchers ${ }^{11,14-16}$ indicated that natural fibers, especially plant fibers, are a 
possible replacement for synthetic fibers. The extraction and production process of the plant fibers are almost free of contaminants. Furthermore, all residues coming from the leftovers during fiber processing are non-toxic and nonhazardous. In a study, Joshi et al. ${ }^{17}$ stated that composites made with natural fibers are environmentally better than the synthetic fiber composites, in most cases, in terms of the performance indicators. The cultivation of natural fibers is dependent on solar energy and the fiber extraction and production process require only a small amount of fossil fuel energy. However, the synthetic fiber production processes require a massive amount of fossil fuel which causes an obvious environmental problem. In addition to the environmental advantages of natural fibers over synthetic fibers, Wambua et al. ${ }^{18}$ concluded that the mechanical properties of the natural fiber composites are fairly comparable to those of glass fiber composites. Furthermore, few specific properties of the natural fiber composites have been reported to be superior to the glass fiber composites. Nevertheless, natural plant fibers are also regarded as the best choice for commercial purposes. ${ }^{19}$

\section{Classification of natural fiber}

According to the origin, natural fibers may be classified as plant fibers, mineral fibers and animal fibers. The plant or vegetable fibers are often termed as cellulosic fibers. These fibers can be further sub-divided into non-wood natural fibers and wood natural fibers. Non-wood natural fibers can be divided into bast, leaf, seed, straw and grass fibers. Among all natural fibers, plant fibers are the ones generally used in the composite industry as reinforcement. A common natural fiber classification is shown in Figure 1.

Figure 1. Classification of natural fiber.

\section{Flax natural fiber-an important bast fiber}

Flax fiber is considered as the most important member of the bast family for composite reinforcement due to its unique properties. ${ }^{7}$ The bast fibers are collected from the fibrous bundles which are situated in the inner bark of a plant stem. The inherent high strength and stiffness of flax fiber and low elongation to failure are the important characteristics of this fiber that make it particularly interesting in composite research. Flax (Linum usitatissimum) is typically grown in a moderate climate region. Charlet et al. ${ }^{20}$ reported that flax plants are cultivated widely in Western Europe where the daily temperature is below $30^{\circ} \mathrm{C}$ generally. However, flax is also grown in Southern Europe, Argentina, India, China, and Canada. Flax fibers are not continuous fibers as compared to the synthetic fibers, but they have a structure similar to that of composites and are hierarchically organized. Their macroscopic properties arise from their micro and nano-structural level. Flax is an important industrial fiber that has been used since ancient time. More than 30,000 years ago, prehistoric hunters were using twisted wild flax fibers for making cords for hafting stone tools, weaving baskets, or sewing garments. ${ }^{21}$ 


\section{Structure and composition of flax fiber}

A flax stem has the constituents of bark, phloem, xylem and a void at the center. The fibers are located as fiber bundles in the outer surface of the plant stem as shown in Figure 2. The flax plants can grow to heights of 80 to $150 \mathrm{~cm}$ in less than 110 days since the plants are fast growing by nature. The bundles (technical fibers) are between 60 and $140 \mathrm{~cm}$ long and their diameter ranges from 40 to $80 \mu \mathrm{m}$. A flax stem contains $20-50$ bundles in its cross section. Each bundle consists of 10-40 spindle-shaped single (elementary) fibers of $1-12 \mathrm{~cm}$ long and $15-30 \mu \mathrm{m}$ in diameter. ${ }^{22}$ Charlet et al. ${ }^{23}$ reported that the elementary fiber diameters are different if taken from the bottom, the middle and the top part of the flax stems. The mean fiber diameter was found to decrease from the bottom to the top of the stems.

Figure 2. Structure of the flax fiber: (a) cross section of flax plant stem and position of the bundles of elementary fibers and technical fibers after extraction,

(b) SEM image of a technical fiber with its constituting elementary fibers (reproduced with permission from ${ }^{24}$ ).

Figure 3. An elementary fiber structure (reproduced with permission from $^{29}$.

The elementary fiber (Figure 3) denotes a single cell in the flax plant. Each elementary fiber is composed of concentric cell walls which are different from each other in terms of thickness and the arrangement of their constituents. Each cell wall consists of what is known as a primary (outer) and a secondary cell wall. These are concentric cylinders with a small open channel in the middle called a lumen. The primary cell wall can be up to $0.2 \mu \mathrm{m}$ thick and the lumen can be as small as $1.5 \%$ of the fiber cross-section. The secondary cell wall contains three sub-layers $S_{1}, S_{2}, S_{3} .{ }^{25}, 26$ The single flax fibers have been shown to possess different shapes within cross-sections along the fiber axis, which some researchers approximated to hexagonal or pentagonal cross-sections. ${ }^{27}$ However, the fibers vary in their non-uniform geometrical shapes along the axis. Owing to these irregularities in the thickness of the cell walls, the fibers vary greatly in strength. ${ }^{26}$

The main constituents of flax fibers are cellulose, hemicellulose, lignin and pectin. A small percentage of wax, oil and structural water are also found. ${ }^{9,}{ }^{28}$ Both primary and secondary cell walls are composed of cellulosic materials. Cellulose fibrils (diameter between $0.1 \mu \mathrm{m}$ and $0.3 \mu \mathrm{m}$ ) are surrounded by concentric lamella, composed of about $2 \%$ pectin and $15 \%$ hemicellulose, which contribute to the thermal degradation and water uptake behavior of the fibers. ${ }^{30}$ The secondary cell wall is the major part of the fiber diameter and $S_{2}$ layer is its dominating constituent. This layer consists of highly crystalline cellulose microfibrils bounded by lignin and hemicellulose. The microfibrils in the $S_{2}$ layer follow a spiral pattern at an angle of $5-10^{\circ}$ along the fiber axis, which explains the stiffness and strength of the fiber in the axial direction. The middle lamella is considered to be the matrix which bonds the cell together. ${ }^{26}$ Bos et al. ${ }^{26}$ described the technical fibers, which are extracted by partially separating the fiber bundles in the flax plant and can be as long as the stem length (approximately $1 \mathrm{~m}$ ). The technical fibers (i.e., the bundles of elementary fibers) consist of 10-40 elementary fibers in the cross- 
section. The elementary fibers overlap for a considerable length and are glued together by an interphase known as a middle lamella, consisting mainly of pectin and hemicellulose which is a mixture of lower molecular weight branched polysaccharides. Table 1 illustrates the composition and mechanical properties of flax and other bast fibers.

Table 1. Bast fibers: compositions, physical and mechanical properties. ${ }^{1,31-33}$

\section{Factors affecting the properties of flax fibers}

Flax is investigated at the elementary and technical fiber level. The great variability reported for flax fiber properties (tensile strength and modulus of elasticity, among others) is a consequence of many factors, including plant origin and growth conditions, plant age, location in the stem and a non-uniform crosssection of all the fibers. Due to this inherent variability, a Weibull distribution function was used to describe the tensile strength of the flax fibers. ${ }^{34-37}$

Charlet et al. ${ }^{23}$ found that mechanical properties of flax fibers were influenced by the location in the stem. Flax fibers located at the bottom of the stem display the poorest mechanical properties, while the fibers located in the middle are the ones that show the best mechanical performance. The biochemical analysis confirmed that both cellulose and non-cellulosic polymers are to be found prolifically in most extensive contents of the middle fibers. Cellulose is considered as the equivalent reinforcing material of a composite structure, whereas noncellulosic materials are the matrix constituent that supports the exchange of load from one microfibril to another. Bos et al. ${ }^{26}$ reported that the technical fiber strength decreases when the clamping length increases because of the similar compositelike structure of this fiber. They performed tensile tests to determine the strength of elementary and technical flax fibers and found that elementary flax fibers showed a considerably higher strength than technical fibers of the same length due to a bundling effect. During testing of the technical fiber bundle, it was found that all elementary fibers are not firmly bonded with the matrix constituents, which happens especially in the secondary cell wall region. As a result, less efficient stress transfer was found in the tensile tests, producing reduced strength as compared to elementary fibers. These results are quite consistent with Bensadoun et al. ${ }^{24}$

Fiber extraction methods also influence the mechanical properties of the flax fibers. Bos et al. ${ }^{26}$ revealed that the tensile strength of the fibers is dependent on the isolation procedure, with manually isolated fibers being stronger than mechanically isolated ones. The mechanical processes of fiber extraction were found to induce kink bands in the fibers, thus reducing their tensile strength. However, they noted that the scatter in strength is much larger for the elementary fibers isolated by hand than for the standard mechanically isolated ones. They claimed that the mechanical fiber processing methods generate a number of large defects, which reduces the scatter in the fiber strength, although the fibers show a lower mean strength. In a different study ${ }^{38}$ of elementary flax fiber tensile tests, it was found that fibers separated by enzyme treatment may receive less damage than mechanical processes. Zeng et al. ${ }^{39}$ introduced a new method of fiber extraction from $35 \%$ aqueous ammonia pre-treated flax stems, comparing this with a standard extraction process. They found both tensile and flexural properties of 
flax fibers were increased due to the ammonia treatment. The average tensile strength of ammonia treated fibers was almost $50 \%$ higher than the one obtained with the commercial extraction processes. In addition, higher flexural toughness was also evident for the ammonia treated fibers.

The tensile strength of the elementary flax fibers was tested by Baley et al. ${ }^{40}$, who found that fiber kink bands and micro-compression defects were the main cause of strength reduction. These two defects act as points of fracture initiation during fiber failure. Both the tensile strength and Young's modulus decreased when the fiber diameter was increased with associated fiber defects. The effect of fiber diameters on fiber strength is shown in Figure 4. However, there was no clear relation between the tensile strength and the number and shapes of the kink bands. In a different study, Baley et al. ${ }^{41}$ analyzed the effect of a drying stage on the tensile strength of the elementary flax fibers and found it to decrease after drying.

Figure 4. Effect of fiber diameter on fiber strength (reproduced with permission from ${ }^{40}$ ).

Among the different factors affecting the fiber properties, moisture absorption and its effects on the fiber properties have been investigated by many authors and the main findings are presented in the following sub-sections.

\section{Moisture absorption of flax fibers}

Most of the bast fibers have almost similar structures and constituents. Moisture susceptibility is treated as one of the main problems in the usage of these fibers. As cellulose and hemicellulose are the dominant constituents of the plant fibers, so hydrogen bonds exist between the molecules of the fiber cell wall. Cellulose and hemicellulose consist of a large hydroxyl $(\mathrm{OH})$ to carbon $(\mathrm{C})$ ratio. Cellulose also consists of a highly crystalline region and it may not be possible for water molecules to enter. However, water molecules diffuse into the amorphous regions of the cellulose and hemicellulose and break inter-molecular hydrogen bonds. This allows an increase in the inter-molecular distance of the cellulose chains, which causes fiber swelling. Either a nano-layer can be formed in between the fibers where a close association was seen with the $\mathrm{OH}$ groups, or a multilayer can be generated where all the water molecules might not intimately relate with the $\mathrm{OH}$ groups. ${ }^{42}$ It is known that the water holding capacity correlates strongly with the volume and structure of the pores in the fiber wall. The uptake of water has been considered the sum of two components: flow into the capillaries (pore absorption); and penetration into the fibers (fiber absorption). The fiber absorption accounts for an increase in fiber thickness during penetration.

Figure 5. Equilibrium moisture absorption of flax sliver at different $\mathrm{RH}$ (reproduced with permission from ${ }^{43}$ ).

Zhang et al. ${ }^{43}$ studied the moisture absorption mechanism of flax fibers exposed to different humid environments. They found a linear relationship between the equilibrium moisture content and the surrounding $\mathrm{RH}$ until it reaches $70 \% \mathrm{RH}$ and, after that value, moisture absorption was found to increase sharply (Figure 
5). More than $10 \%$ of the air's moisture content can be absorbed by flax fibers within one hour at $90 \% \mathrm{RH}$. These results are quite consistent with a recent study ${ }^{44}$, where researchers found equilibrium moisture absorption is almost double $(14.3 \%)$ at $95 \% \mathrm{RH}$ than that at $70 \% \mathrm{RH}$. Interestingly, all the fibers reached the equilibrium moisture content at ambient temperature within 60 minutes regardless of the $\mathrm{RH}$ value (Figure 6).

Figure 6. Moisture absorption kinetics of flax fibers at different $\mathrm{RH}$ (reproduced with permission from ${ }^{44}$ ).

A detailed investigation of such environmental effects on duralin (treated) and green (raw) flax fibers was carried out by Stamboulis et al. ${ }^{29,} 45$ They found $3 \%$, $15 \%$ and $24 \%$ moisture contents in the flax fibers when exposed to $20 \%, 66 \%$ and $93 \% \mathrm{RH}$ environments, respectively, and the absorption curves followed typical Fickian behavior. However, when the fibers were exposed to $100 \% \mathrm{RH}$, the absorption mechanism changed, and did not behave according to Fick's law. Basically, they observed an absorption curve that increased in a stepped manner, reaching different equilibrium levels (showing a maximum of $42 \%$ moisture content). They attributed this behavior to swelling stresses that develop during moisture absorption and relax after a certain time once the first equilibrium is reached, changing the equilibrium moisture condition. In a different study ${ }^{46}$, the absorption-desorption equilibrium for flax fibers at $21^{\circ} \mathrm{C}$ and $40 \% \mathrm{RH}$ was reached in 40 minutes and in 40-45 minutes for hemp fibers with the same conditions. Similar findings were found in a previous study ${ }^{47}$, where flax fibers reached the moisture equilibrium after $28.5,34$ and 37 minutes during a drying stage at $80^{\circ} \mathrm{C}$, $60^{\circ} \mathrm{C}$ and $40^{\circ} \mathrm{C}$ respectively.

\section{Effect of moisture absorption on properties of flax fibers}

Moisture absorption and its effects on flax fibers have been investigated in detail due to their excellent mechanical properties and extensive use in the composite manufacturing process. Nilsson ${ }^{48}$ reported that the moisture content in natural fibers has a great influence on their stiffness. Davies and Bruce $^{34}$ found that the tensile modulus of flax fibers is strongly dependent on the environmental $\mathrm{RH}$, both static and dynamic moduli of flax fibers decreasing remarkably with an increase in RH. Specifically, they considered four different $\mathrm{RH}$ (between $30 \%$ and $70 \%$ ) during their experiments and found that the static modulus showed a decreasing trend with increasing $\mathrm{RH}$ at a rate of $0.39 \mathrm{GPa} / \% \mathrm{RH}$ for a single flax fiber. Fiber strain was independent of static modulus, but dynamic modulus displayed an increasing rate with an increasing strain at a rate of $13 \% \mathrm{GPa} / \%$ strain. This phenomenon was confirmed by Baley ${ }^{27}$. In another study, Baley et al. ${ }^{41}$ also investigated the effects of absorbed water on the tensile properties of elementary flax fibers. They carried out tensile tests on 'as received' raw fibers, dried fibers and dried fibers in contact with ambient air where moisture was absorbed. The experimental analysis confirmed that in each case, fibers were damaged, which reduced their mechanical properties. Surprisingly, moisture absorbed raw flax fibers presented higher tensile strength than the fibers subjected to drying stages. They concluded that the cohesion between the matrix and the 
microfibrils is lost after drying, potentially leading to a decrease in tensile strength. Mustata and Mustata ${ }^{46}$ studied the moisture equilibrium in yarns of flax and hemp fibers finding a higher tensile strength in the wet yarns than the dry ones for both fibers. Joffe et al. ${ }^{38}$ revealed that strain at failure increased with moisture penetration at the fiber cell wall and is the outcome of the plasticizing effect of absorbed water on a flax fiber. Netravali ${ }^{49}$ also found that fiber strength can be significantly decreased with continuous moisture absorption and desorption cycles.

Stamboulis et al. ${ }^{29}$ observed the changes in the structure of the fibers as they were exposed to high humidity levels. The surface of dry fibers was smooth, and the fibrils were well connected by the organic matrix forming a bundle, while the $100 \% \mathrm{RH}$ conditioned fibers were swollen, and their surface was rougher than that of the dry ones. In addition, the individual fibrils were more separated and some damage in the form of kink bands were observed. These observations strongly suggest that properties of composites manufactured with natural fiber fabrics having different moisture contents could vary significantly.

\section{Flax fiber reinforced composites}

Elementary flax fibers are processed into the form of mats, rovings, fabrics, and yarns to use in the manufacturing of composites. After selecting a suitable manufacturing technique, these are combined into several layers with the matrix material of some form of a resin to manufacture composites. The hydrophilic behavior of these fibers and hydrophobic matrix material often affect the adhesion between them. To address this issue, chemical and physical treatment of the fibers is used, e.g., acetylation, alkali treatment, bleaching, peroxide treatment, isocyanate treatment, vinyl grafting, coupling agents, etc. The details of the different treatment processes are out of the scope of this review and can be found in various studies. ${ }^{50-53}$

\section{Suitable matrix selection for flax composites}

Fibers are held together by the matrix in a fiber reinforced composite which is an essential and key consumable for the manufacturing of composites. Temperature is an important factor in resin selection for the flax fiber composites. Summerscales et al. ${ }^{54}$ reported that temperature limits the matrix selection as natural fiber degrades at a higher temperature. In most cases, vegetable fibers start to degrade at $200^{\circ} \mathrm{C}$ or above over time. Therefore, matrix selection for the composite materials is restricted to thermosetting polymers of thermoplastics with a low melting temperature.

Although composites manufactured with thermoplastic matrices are less expensive and recyclable, they possess limited mechanical properties and a higher tooling cost is required. In addition, the directional properties of flax fibers cannot be used completely when randomly oriented short fibers are used with thermoplastics. ${ }^{55}$ Thermosetting matrices offer many advantages like being easy to process (low viscosity), requiring less processing temperature and less expensive. Furthermore, as the impregnation of the fibers is easier, the manufacturing process requires a lower pressure and facilitates a higher loading of fibers. ${ }^{33}$ 
Undoubtedly, epoxy is the most widely used resin in the flax fiber composite manufacturing processes. A variety of benefits can be found in the epoxy-based resins during the manufacturing process. Epoxy possesses excellent mechanical and chemical properties. It also has a high hardness with good heat and waterresistant properties. The shrinkage associated with epoxy resins is extremely low as compared to vinyl esters and polyesters. It also contains excellent adhesive properties and is easy to cure and use. No volatile agents are formed during the curing process, which is a major advantage as compared to phenolic, polyester and vinyl ester resins.

\section{Manufacturing aspects of the flax fiber reinforced composite}

A number of factors require consideration before processing the flax fiber composite: fiber type, fiber content, fiber orientation and the moisture content of the fibers. Engineers would mainly focus on criteria which include the desired properties, size, and shape of the resultant composites, the processing characteristics of raw materials (both fibers and polymers: bio-based or petroleum based). In addition, the production speed and the manufacturing cost required also affect the selection of a proper process to fabricate natural fiber composites. Furthermore, based on the processing techniques, semi-finished product manufacturing; mat production, slivers, fiber yarns, fiber preparation (opening, mixing, and carding), and granule production are the important steps to be taken into account for the production of natural flax fiber composites. ${ }^{56,57}$ The fiber length, aspect ratio (length/diameter of fibers) and the chemical composition of the fibers can also influence their processing.

Several methods are available for manufacturing natural fiber reinforced composites. According to the resin used for these composites, it is suitable to divide the bio-composites into thermoplastic and thermoset matrix-based composites. Usually, traditional manufacturing techniques can be used to manufacture natural fiber thermoplastic composites: compounding, mixing, extrusion, injection molding and compression molding. On the other hand, natural fiber reinforced thermoset composites are usually manufactured by liquid composite molding (LCM) processes. Resin transfer molding (RTM), vacuum infusion ( $\mathrm{VI}$ ), injection compression molding (ICM), sheet molding, pultrusion, reaction injection molding, bulk molding compound are some examples of LCM. Francucci et al. [58] presented a comprehensive review on the manufacturing of vegetable fiber composites by LCM techniques. Some LCM methods are illustrated in Table 2.

Table 2. Liquid composite molding processes (reprinted with permission ${ }^{58}$ ).

Oksman el al. ${ }^{59}$ studied the influence of fiber microstructure on the mechanical properties of extruded composite materials. They used jute and enzyme treated flax fibers to reinforce polypropylene (PP). The composite materials were manufactured via a long fiber thermoplastic (LFT) processing method whereby rovings were continuously fed into an extruder. A twin-screw extruder was utilized to compound the samples and PP plastic. A temperature profile of $180-200^{\circ} \mathrm{C}$ between the feeding zone and the die was maintained to ensure complete and homogenous mixing. As expected, the authors observed an 
increased flexural stiffness when the fiber loading was increased. It was noted that the use of $2 \%$ maleated PP significantly improved the composite properties because of the better compatibility in the mixing process.

In a different study, Oksman el al. ${ }^{60}$ studied flax fiber reinforced polylactic acid (PLA) composites manufactured by compression molding (CM). They found the PLA based composite has $50 \%$ better strength than the conventional flax/PP composites. In contrast, a microscopy study of the microstructure confirmed the poor adhesion between the fibers and the PLA matrix. The researchers found no difficulty in processing flax/PLA composites with a traditional manufacturing process and this composite can be processed in a similar way as flax/PP composites.

Pultrusion and RTM are two of the most common processes used to make thermosetting composite materials. Pultrusion can be assumed as a continuous process for producing long profiles made of composite materials. Reinforcing fibers are saturated with the liquid resin, and then pulled through a heated die to form a composite with a specific shape and dimensions. Angelov et al. ${ }^{61}$ were one of the first to pultrude flax fibers into a fixed shape. They varied the preheating and die temperatures while pulling the flax fibers and PP yarns. After passing through the preheating zone (approximately $600 \mathrm{~mm}$ at temperatures of $155-166^{\circ} \mathrm{C}$ ), the profile was pulled through the die. The temperature of the hot die was tested at $200^{\circ} \mathrm{C}$ and $210^{\circ} \mathrm{C}$. After the hot die, the polymer passed into the cold die that was maintained at room temperature. The pulling speed was varied from 8 to 38 $\mathrm{cm} / \mathrm{min}$. The authors concluded that similar mechanical performance can be obtained in the pultrusion process as compared to the composites manufactured by CM.

In addition, RTM is also a processing technique suitable for manufacturing high quality natural fiber reinforced composites. In a related study ${ }^{62}$, arctic flax fibers and epoxy resin were used as reinforcement and matrix respectively. A comparison between the obtained mechanical properties of the materials showed that the composite with $50 \%$ arctic flax has significantly more stiffness (40 GPa) compared to that of pure epoxy (3.2 GPa). A similar pattern was observed in the tensile strength of composites compared to the neat epoxy. This study verifies that RTM is a suitable processing method for natural fiber composites based on epoxy resins.

\section{Effect of RH, moisture and water on flax fiber composites}

Since flax fibers are highly hydrophilic, the $\mathrm{RH}$ has a vital role on the fiber reinforced composites. Generally, moisture absorption of the flax fibers increases with increasing $\mathrm{RH}$. Immersion of the composites under water boosts water absorption and the water molecules diffuse within the composite materials and affect them by swelling.

\section{Moisture present in the fibers prior to manufacturing the composites}

In general, moisture in fibers is considered to be detrimental to composite performance. The flax fiber fabrics are usually dried before the manufacturing stage, which would likely be beneficial for the quality of the obtained composites. ${ }^{61}$ However, Baley et al. ${ }^{63}$ proved that drying the fibers (for 14 hours at $105^{\circ} \mathrm{C}$ ) results 
in a significant loss of strength (44\% on average) and failure strain (39\%). They also performed tensile tests on unidirectional (UD) flax/epoxy composites, where reinforcement was dried and 'as-received' flax fibers. It was found that drying did not affect the axial stiffness but caused a large drop (36\%) in composite strength, in a similar way to the drop found in fiber strength. Furthermore, they postulated that the removal of moisture would also influence the properties of the fiber surfaces and hence, the interfacial bonding. Therefore, they suggested that a more detailed study was necessary to optimize the conditioning of plant fiber fabrics in order to obtain the highest quality composites.

Recently, Fuentes et al. ${ }^{64}$ studied the influence of moisture present in the environment during the manufacturing of flax fiber-unsaturated polyester (UP) composites on their performance. They compared the performance of the composites which were manufactured under dry and $100 \% \mathrm{RH}$ conditions. Results were an $18 \%$ and $25 \%$ reduction in tensile strength and modulus in dry conditions and $11 \%$ and $8 \%$ reduction in flexural strength and modulus when the composites were manufactured at $100 \% \mathrm{RH}$. This fact was related to the decrease of the fibers' mechanical properties due to the softening and possible dissolution of the interface between the elementary fibers.

Moudood et al. ${ }^{44}$ reported the effects of moisture present in the fibers prior to manufacturing flax fiber reinforced epoxy composites by a vacuum infusion process. Composite panels manufactured with flax fibers taken from $70 \% \mathrm{RH}$ and 95\% RH environments showed severe warpage. They suggested that as the fibrous preform was in a swollen state when compacted by the vacuum bag and some of the moisture was gradually extracted during the infusion process (drawn away by the vacuum and dissolved in the resin), this cause fiber shrinkage. Thus, residual compressive stresses developed during the curing process, which ultimately led to part warpage after demolding. The fiber-matrix interface became weaker due to high moisture content in the fibers and porosity was increased in the microstructure of the composites. Although the fiber-matrix interface was affected, the optimum tensile strength was found at composites made with $50 \%$ $\mathrm{RH}$ conditioned fabrics and, below and above that value, the tensile strength of the composites was decreased. This was explained by water molecules increasing the tensile strength of the fibers but at the same time negatively affecting the fibermatrix interface and overall microstructural condition. The researchers also indicated that the plasticizing effect of water molecules on flax fibers significantly increased the strain at break and decreased Young's modulus. On the other hand, the flexural strength and modulus decreased continuously with increasing $\mathrm{RH}$. Furthermore, composites made with fibers conditioned at 95\% RH showed a sharp drop in mechanical properties (Young's modulus, flexural strength and modulus).

The effect of $\mathrm{RH}$ in the fabrication of flax/UP composites on interfacial shear strength (IFSS) and flexural properties was investigated by Zhang et al. ${ }^{43}$ The IFSS of the composites started to drop sharply at $70 \% \mathrm{RH}$ and ended up with a more than six-fold reduction at $90 \% \mathrm{RH}$. Therefore, this study concluded that $\mathrm{RH}$ should be less than $70 \%$ to manufacture a composite with consistently better quality. 


\section{Water and moisture absorption mechanisms}

Newman ${ }^{65}$ studied the water absorption process of flax-epoxy composites after being immersed under water. Fiber swelling occurs and the matrix material around the fibers is stressed due to water absorption. Next, the matrix molecules' relaxation processes release a few of these stresses. Drying of natural fiber composite materials that have absorbed water results in fiber shrinkage, causing the matrix material to lose contact with the fibers. As a result, a gap is generated between the fibers and the matrix, having a detrimental effect on the interfacial properties. The author explained this phenomenon as an auto accelerative process where the drying cycle enhances the water damage which increases the rate of fiber shrinkage. In contrast, the shrinking process of the matrix material is relatively slow and therefore, stress is released by the generated microcracks within the fibers and at the fiber-matrix interfaces. This water absorption mechanism with debonding is shown schematically in Figure 7.

Figure 7. Debonding process in fiber/matrix interface with water (reproduced with permission from ${ }^{66}$ ).

The water and moisture absorption behavior of flax fiber reinforced composites depend on the surrounding temperature, the humidity present in the environment and also on the nature of the composite. The water molecules spread in the composite by a diffusion mechanism inside the matrix. Sometimes micropores and cracks that are generated within the matrix or even the capillarity transport along the fiber-matrix interface can enhance the diffusion rate. The diffusion behavior of the polymeric composites can be divided as Fickian, nonFickian and intermediate. Assarar et al. ${ }^{67}$ studied the water uptake behavior of flax fiber reinforced epoxy composites, reporting that it is Fickian at room temperature. The water absorption behavior of flax-epoxy composites is shown in Figure 8, which is linear initially (Fickian diffusion) but slows down as the moisture content approaches its saturation level. The saturated water absorption at equilibrium is almost $13.5 \%$ for each unit thickness of the composite.

Figure 8. Water absorption pattern of flax-epoxy composites (reproduced with permission from ${ }^{67}$ ).

Cheour et al. ${ }^{68}$ studied the flax-epoxy composites with different fiber orientations to measure the effects of moisture absorption on composite performance. They used water immersion test of composites for three different fiber orientations $\left(0^{\circ}, 45^{\circ}\right.$ and, $\left.90^{\circ}\right)$ and found that fiber orientation has a significant impact on the moisture uptake of flax composites. The UD flax fiber reinforced epoxy composites (FFRE) with fibers at $45^{\circ}$ absorbed the highest amount of water among the different orientations. The FFRE $45^{\circ}$ and FFRE $90^{\circ}$ absorbed $25.1 \%$ and $5.2 \%$ more water respectively than the FFRE $0^{\circ}$ laminate (Figure 9). They explained this fact by stating that water diffusion occurred preferentially both in the fiber direction and thickness directions of the composites. The water diffusion in fiber orientation for FFRE $0^{\circ}$ is negligible as compared to the diffusion in thickness direction due to the fiber length in the composites. However, the fibers are shorter in width for FFRE $45^{\circ}$ and FFRE $90^{\circ}$ samples, which makes water diffusion easier 
in the fiber direction for these composites. This diffusion of water into flax composites with different fiber orientation is illustrated in Figure 10.

Figure 9. Moisture absorption of flax composites with different fiber orientation (reproduced with permission from ${ }^{68}$ ).

Figure 10. Water diffusion of flax composites in different fiber orientation $\left(a=0^{\circ}\right.$, $\left.\mathrm{b}=45^{\circ}, \mathrm{c}=90^{\circ}\right)\left(\right.$ reproduced with permission from $\left.{ }^{68}\right)$.

Recently, Chilali et al. ${ }^{69}$ compared the water uptake behavior of flax fiber reinforced thermoplastic and thermosetting composites. The water absorption behavior was found to be the same as reported for different conditions of the flax composites. The amount of absorbed water increases linearly at the beginning, but the absorption slows down as the saturation level is reached. In addition, flax composites with a thermosetting resin (epoxy) absorb more water than the composites with the thermoplastic resin (acrylic) (Figure 11). Dhakal et al. ${ }^{70}$ compared the water absorption behavior of two natural fiber composites: flax and jute. In order to measure the influence of moisture they conducted water immersion tests for forty days at room temperature and found that saturated moisture contents were $9.61 \%$ and $14.41 \%$ for flax and jute composites respectively. Berges et al. ${ }^{71}$ studied the moisture uptake behavior of UD flax fiber reinforced epoxy laminates, finding their diffusion kinetics follow a one-dimensional Fickian behavior when exposed to hygrothermal conditioning at $70^{\circ} \mathrm{C}$ and $85 \% \mathrm{RH}$. These results were also supported by Scida et al. ${ }^{72}$, who confirmed that flax fiber composites follow a Fickian diffusion mode at similar conditions. The tensile mechanical behavior is clearly affected by the hygrothermal aging which was confirmed by the shape of the stress-strain curves. At $90 \% \mathrm{RH}$ and $20{ }^{\circ} \mathrm{C}$, Young's modulus decreased by $33 \%$ for the first 3 days and a $55 \%$ reduction was found after 38 days.

Figure 11. Water absorption of flax/epoxy and flax/acrylic composites (reproduced with permission from ${ }^{69}$ ).

Different diffusion coefficients for flax fiber reinforced composites are found in different literature as shown in Table 3.

Table 3. Diffusion coefficients of the flax fiber composites according to literature.

Moisture and water absorption of composites - effect on the performance

The moisture content at a given $\mathrm{RH}$ has a substantial effect on flax fiber reinforced composites. Generally, plant fiber reinforced composites have a tendency to significantly decrease their tensile and flexural properties and interfacial strength in wet conditions. ${ }^{2,77}$

The effect of water absorption on the mechanical properties of the flax fiber/bio-epoxy composites has been evaluated by Munoz and Garcia. ${ }^{75}$ This study was done by immersing the samples into water at room temperature. The authors found that fiber content influences the moisture absorption behavior of the composites which have a tendency to absorb more water as the fiber content was 
increased. They further found that water absorbed composites have a higher tensile strength and strain than the dry composite samples. The water absorbed fiber swelling filled the gaps between the fiber-matrix interfaces and the tensile strength was increased up to $35 \%$. The tensile strain also increased due to the plasticization effects of the wet composite samples. In contrast, the flexural strength decreased by $20 \%$ when compared to the dry composites. The researchers concluded that, a higher percentage of water absorption might cause more micro-cracking due to the swelling of the flax fibers which generated a poor fiber-matrix interface during bending loading. However, they observed that the flexural and tensile moduli of the composites decreased with increasing water absorption since these properties depend on fiber properties not on fiber-matrix interface. The findings of this study are opposite to those of Le Duigou et al. ${ }^{78}$ who found that flax/PLA composites degrade both in terms of tensile strength and stiffness when the composite absorbs water molecules. Different matrix materials were used in both studies which might be a reason of this discrepancy.

In many cases, the interfacial strength between the fiber-matrix bonding becomes weaker with increasing moisture content. However, Le Duigou et al. ${ }^{79}$ studied the fiber-matrix interface with water treated flax/PLA and untreated flax/PLA composites. They found both IFSS and frictional stress were increased by $13 \%$ and $30 \%$, respectively, for water treated flax fiber reinforced Poly-L-lactic Acid (PLLA) composites. In general, the fiber roughness properties, chemistry and the surface energy mainly influence the interfacial strength between the fiber and the matrix material. ${ }^{79,80}$

However, in a different study Fuentes et al. [64] reported that the flax fiber surface is susceptible to water absorption due to its amorphous polymer constituents, but the surface energy and IFSS of the flax fiber were both found to be relatively constant at different $\mathrm{RH}$. Nevertheless, they found a reduction in strength of the flax composites at different $\mathrm{RH}$ as the fibers turn soft, thus a dissolution of the interface might occur between the elementary fibers. Scida et al. ${ }^{72}$ pointed out that the matrix material was mainly damaged when the flax fiber composites are aged with $90 \% \mathrm{RH}$ across different time durations. This damage affects the fiber/matrix interfacial bonding and fiber breakage occurs.

Le Duigou et al. ${ }^{8}$ tested the interfacial strength of a single flax fiber/epoxy micro-composite by immersing samples in water for different time durations and found a $60 \%$ reduction of shear strength from their initial value after 135 hours. In an earlier study ${ }^{78}$ of wet (sea water) aging of flax/PLLA composites, they also found the fiber/matrix interfacial strength was damaged due to swelling of the fibers at the interface. The absorbed water can form hydrogen bonding with the fibers which eventually reduce the interfacial bonding. Assarar et al. ${ }^{67}$ also reported the weak fiber-matrix interface of water absorbed flax/epoxy composites when tested with acoustic emission.

\section{Present and future scope of flax fiber composites}

Several unique properties and strength of natural fibers have prompted researchers to become interested in these composites. The renewable resources of plant fibers are experiencing an increasing uptake in different industrial usage. For example, Saheb and $\mathrm{Jog}^{81}$ reported that natural fibers can be used in composites which have various applications from normal appliances to space- 
craft. Specifically, the flax fiber industrial supply is increasingly being used for manufacturing composite materials.

Suddell and Evans ${ }^{82}$ reported that flax fiber composites are widely used in the automotive and other transport industries. For instance, several automotive components previously manufactured with glass fibers are being replaced by these fibers and flax fibers can also be used in car disk brakes to replace asbestos. George et al. ${ }^{83}$ stated that the advantage of these fibers over synthetic ones in automotive interior components is that the natural fiber composite automotive parts can be ruptured instead of splintering during failure of the structures if an accident occurs. In addition, these fibers lead to lighter parts and as a consequent reduction in fuel consumption, which has economic and environmental advantages.

Flax Fiber reinforced composites are widely used in sports industries (bicycle frames, stand-up paddle boards, most kind of boards, etc.), and the maritime industry (small to medium sized boats). In addition, flax prepregs with heavy areal weight $\left(300\right.$ to $\left.550 \mathrm{gm} / \mathrm{m}^{2}\right)$ are in developmental phases for future application in the aeronautical industry. ${ }^{82}$ Flax fiber composites are also used with concrete structures for building construction materials to enhance the structural strength. ${ }^{84}$

\section{Summary and concluding remarks}

The growing trend of flax fiber usage in the composite industry has proved it to be a potential candidate to draw more interest among researchers. Due to its wide range of applicability in various industries, it is important to understand what factors affect the properties of flax fiber reinforced composites. Flax fibers have an intrinsic variability in their physical and mechanical properties, which must be considered when designing structural parts. Moisture and water absorption are two key factors responsible for the deterioration of the composite. Some key points of the effects of moisture and water content on the properties of the flax fibers and their composites can be summarized as follows:

1. Moisture present in flax fiber fabrics before manufacturing the composites affects the final microstructure and properties of the obtained material. The microstructure of the composite materials is negatively affected by moisture in the fabrics, leading to pores and fiber debonding from the matrix. Flexural strength continuously decreases as the moisture in the fabrics is increased, but the tensile strength is shown to have an optimum value due to two opposite effects: the positive effect of water molecules on the tensile properties of the fibers and the deterioration of the overall composite microstructure (pores, poor interface, etc.). When the moisture content in the fibers is higher, both Young's modulus and the flexural modulus decrease, while the strain at break increases because of plasticization effects.

2. Due to the preferential water transport paths alongside the fiber direction, fiber orientation with respect to the thickness direction of samples has a significant effect on the water absorption behavior of the composites. Composites having the fibers oriented perpendicular to the thickness 
direction show the least water uptake, while using fibers oriented at $45^{\circ}$ causes the most water absorption.

3. In some cases, superior mechanical properties were observed in composites having moisture absorbed flax fibers than dried fibers. Swelling of flax fibers in the composites can improve their tensile strength as this could fill the gap in the interface, increasing friction and thus the interfacial strength. However, the flexural strength was found to decrease as the moisture content of the fibers increases.

4. Both the fibers and the composites follow a one-dimensional Fickian diffusion behavior during the absorption of water molecules at high humidity and temperature, except at $100 \% \mathrm{RH}$.

5. If the composites have been immersed under water or exposed to high $\mathrm{RH}$ for a long time, fiber swelling at the interface can damage the fiber/matrix interfacial strength, by letting water remove water soluble substances from the fibers and also by establishing hydrogen bonds between the water molecules and the $\mathrm{OH}$ present in the fibers.

6. It is well established that physical and chemical treatments improve the moisture absorption property of flax fibers which will increase the quality of the composites. However, further study is still needed to reduce the moisture absorption behavior of the fibers and their composites. Furthermore, the influence of moisture on the fiber/matrix interfacial strength still needs some attention. This will extend the usage of flax fiber reinforced composites in precise engineering applications such as aeronautical and automotive parts.

\section{References}

1. Cristaldi G, Latteri A, Recca G and Cicala G. Composites Based on Natural Fibre Fabrics. In: Dubrovski PD (ed.) Woven Fabric Engineering. Ch. 17. Rijeka: InTech, 2010, pp. 317-342.

2. Dhakal HN, Zhang ZY and Richardson MOW. Effect of water absorption on the mechanical properties of hemp fibre reinforced unsaturated polyester composites. Compos Sci Technol 2007; 67: 1674-1683.

3. Monteiro S, Candido V, Braga F, et al. Sugarcane bagasse waste in composites for multilayered armor. Eur Polym J 2016; 78: 173-185.

4. Summerscales J, Dissanayake N, Virk A and Hall W. A review of bast fibres and their composites. Part 2-Composites. Compos Part A-Appl S 2010; 41: 1336-1344.

5. Nishino T. Natural fibre sources. In: Baillie C (ed.) Green composites: Polymer composites and the environment. Ch. 4. Cambridge: Woodhead Publishing Limited, 2004, pp. 49-80.

6. Weclawski BT and Fan M. Bast Fibers Composites for Engineering Structural Applications: Myth or the Future Trend. In: Thakur VK (ed.) Green Composites from Natural Resources. Ch. 7. Boca Raton: CRC Press, 2013, pp.133-156. 
7. Yan L, Chouw N and Jayaraman K. Flax fibre and its composites - A review. Compos Part B-Eng 2014; 56: 296-317.

8. Le Duigou A, Davies $\mathrm{P}$ and Baley C. Exploring durability of interfaces in flax fibre/epoxy micro-composites. Compos Part A-Appl S 2013; 48: 121-8.

9. Celino A, Freour S, Jacquemin F and Casari P. The hygroscopic behavior of plant fibers: a review. Front Chem 2014; 1: 1-12.

10. Kalia S, Kaith BS and Kaur I. Pretreatments of Natural Fibers and their Application as Reinforcing Material in Polymer Composites-A Review. Polym Eng Sci 2009; 49: 1253-1272.

11. Venkateshwaran $\mathrm{N}$ and Elayaperumal A. Banana Fiber Reinforced Polymer Composites - A Review. J Reinf Plast Comp 2010; 29: 2387-2396.

12. Alves C, Ferrao PMC, Silva AJ, et al. Ecodesign of automotive components making use of natural jute fiber composites. J Clean Prod 2010; 18: 313-327.

13. Pickering SJ. Recycling technologies for thermoset composite materials-current status. Compos Part A-Appl S 2006; 37: 1206-1215.

14. Yang YX, Boom R, Irion B, et al. Recycling of composite materials. Chem Eng Process 2012; 51: 53-68.

15. Biagiotti J, Puglia D and Kenny JM. A review on natural fibre-based composites-part I: structure, processing and properties of vegetable fibres. J Nat Fibers 2004; 1: 3768.

16. Suddell BC, Evans W, Isaac D and Crosky A. A survey into the application of natural fiber composites in the automotive industry. In: Proceedings of Fourth International Symposium on Natural Polymers and Composites, São Pedro, Brazil, 2002; pp.455460.

17. Joshi SV, Drzal L, Mohanty A and Arora S. Are natural fiber composites environmentally superior to glass fiber reinforced composites? Compos Part A-Appl S 2004; 35: 371-376.

18. Wambua P, Ivens J and Verpoest I. Natural fibres: can they replace glass in fibre reinforced plastics? Compos Sci Technol 2003; 63: 1259-1264.

19. Eichorn S, Baillie C, Zafeiropoulos N, et al. Current international research into cellulosic fibres and composites. J Mat Sci 2001; 36: 2107-2131.

20. Charlet K, Jernot JP, Eve S, et al. Multi-scale morphological characterisation of flax: From the stem to the fibrils. Carbohyd Polym 2010; 82: 54-61.

21. Kvavadze E, Bar-Yosef O, Belfer-Cohen A, et al. 30,000-Year-Old Wild Flax Fibers. Science 2009; 325: 1359.

22. Müssig J and Stevens C. Industrial Applications of Natural Fibres: Structure, Properties and Technical Applications. New York: John Wiley \& Sons, 2010.

23. Charlet K, Baley C, Morvan C, et al. Characteristics of Hermes flax fibres as a function of their location in the stem and properties of the derived unidirectional composites. Compos Part A-Appl S 2007; 38: 1912-1921.

24. Bensadoun F, Verpoest I, Baets J, et al. Impregnated fibre bundle test for natural fibres used in composites. J Reinf Plast Comp 2017; 36: 942-957.

25. Bos HL and Donald AM. In situ ESEM study of the deformation of elementary flax fibres. J Mater Sci 1999; 34 : 3029-3034.

26. Bos HL, Van den Oever MJA and Peters OCJJ. Tensile and compressive properties of flax fibres for natural fibre reinforced composites. J Mater Sci 2002; 37: 1683-1692.

27. Baley C. Analysis of the flax fibres tensile behaviour and analysis of the tensile stiffness increase. Compos Part A-Appl S 2002; 33: 939-948. 
28. Komuraiah A, Kumar NS and Prasad BD. Chemical Composition of Natural Fibers and its Influence on their Mechanical Properties. Mech Compos Mater 2014; 50: 359376.

29. Stamboulis A, Baillie CA and Peijs T. Effects of environmental conditions on mechanical and physical properties of flax fibers. Compos Part A-Appl S 2001; 32: 1105-1115.

30. Huang XS and Netravali A. Characterization of flax fiber reinforced soy protein resin based green composites modified with nano-clay particles. Compos Sci Technol 2007; 67: 2005-2014.

31. John MJ and Thomas S. Biofibres and biocomposites. Carbohyd Polym 2008; 71: 343364.

32. Satyanarayana KG, Ravikumar KK, Sukumaran K, et al. Structure and Properties of Some Vegetable Fibers .3. Talipot and Palmyrah Fibers. J Mater Sci 1986; 21: 57-63.

33. Thakur VK and Thakur MK. Processing and characterization of natural cellulose fibers/thermoset polymer composites. Carbohyd Polym 2014; 109: 102-117.

34. Davies GC and Bruce DM. Effect of environmental relative humidity and damage on the tensile properties of flax and nettle fibers. Text Res $J$ 1998; 68: 623-629.

35. Zafeiropoulos NE and Baillie CA. A study of the effect of surface treatments on the tensile strength of flax fibres: Part II. Application of Weibull statistics. Compos Part A-Appl S 2007; 38: 629-638.

36. Virk AS, Hall W and Summerscales J. Failure strain as the key design criterion for fracture of natural fibre composites. Compos Sci Technol 2010; 70: 995-999.

37. Hu W, Ton-That MT, Perrin-Sarazin F and Denault J. An Improved Method for Single Fiber Tensile Test of Natural Fibers. Polym Eng Sci 2010; 50: 819-825.

38. Joffe R, Andersons $\mathrm{J}$ and Wallstrom L. Strength and adhesion characteristics of elementary flax fibres with different surface treatments. Compos Part A-Appl S 2003; 34: 603-612.

39. Zeng XS, Mooney SJ and Sturrock CJ. Assessing the effect of fibre extraction processes on the strength of flax fibre reinforcement. Compos Part A-Appl S 2015; 70: $1-7$.

40. Baley C. Influence of kink bands on the tensile strength of flax fibers. J Mater Sci 2004; 39: 331-334.

41. Baley $\mathrm{C}$, Morvan $\mathrm{C}$ and Grohans $\mathrm{Y}$. Influence of the absorbed water on the tensile strength of flax fibers. Macromol Symp 2005; 222: 195-201.

42. Zafeiropoulos NE. Interface Engineering of Natural Fibre Composites for Maximum Performance. Cambridge: Woodhead Publishing Limited, 2011.

43. Zhang DH, Milanovic NR, Zhang YH, et al. Effects of humidity conditions at fabrication on the interfacial shear strength of flax/unsaturated polyester composites. Compos Part B-Eng 2014; 60: 186-92.

44. Moudood A, Hall W, Öchsner A, et al. Effect of Moisture in Flax Fibres on the Quality of their Composites. J Nat Fibers 2017:1-16.

45. Stamboulis A, Baillie CA, Garkhail SK, et al. Environmental durability of flax fibres and their composites based on polypropylene matrix. Appl Compos Mater 2000; 7: 273-294.

46. Mustata A and Mustata FS. Moisture Absorption and Desorption in Flax and Hemp Fibres and Yarns. Fibres Text East Eur 2013; 21: 26-30.

47. Nair G, Liplap P, Gariepy Y and Raghavan G. Microwave drying of flax fibre at controlled temperatures. J Agric Sci Technol B 2011; 1: 9-21. 
48. Nilsson T. Micro Mechanical Modelling of Natural Fibres for Composite Materials, PhD Thesis, Lund University, Sweden, 2006.

49. Netravali AN and Chabba S. Composites get greener. Mater today 2003; 6: 22-29.

50. Kabir MM, Wang H, Lau KT and Cardona F. Chemical treatments on plant-based natural fibre reinforced polymer composites: An overview. Compos Part B-Eng 2012; 43: 2883-2892.

51. John MJ and Anandjiwala RD. Recent developments in chemical modification and characterization of natural fiber-reinforced composites. Polym Compos 2008; 29 :187207.

52. Mohanty AK, Misra M and Drzal LT. Surface modifications of natural fibers and performance of the resulting biocomposites: An overview. Compos Interface 2001; 8 :313-343.

53. Li X, Tabil LG and Panigrahi S. Chemical treatments of natural fiber for use in natural fiber-reinforced composites: A review. J Polym Environ 2007; 15 :25-33.

54. Summerscales J, Dissanayake NPJ, Virk AS and Hall W. A review of bast fibres and their composites. Part 1-Fibres as reinforcements. Compos Part A-Appl S 2010; 41: 1329-1335.

55. Gning PB, Liang S, Guillaumat L and Pui WJ. Influence of process and test parameters on the mechanical properties of flax/epoxy composites using response surface methodology. J Mater Sci 2011; 46: 6801-6811.

56. Ho MP, Wang H, Lee JH, et al. Critical factors on manufacturing processes of natural fibre composites. Compos Part B-Eng 2012; 43: 3549-3562.

57. Faruk O, Bledzki AK, Fink HP and Sain M. Progress Report on Natural Fiber Reinforced Composites. Macromol Mater Eng 2014; 299: 9-26.

58. Francucci G and Rodriguez E. Processing of plant fiber composites by liquid molding techniques: An overview. Polym Compos 2016; 37: 718-733.

59. Oksman K, Mathew AP, Langstrom R, et al. The influence of fibre microstructure on fibre breakage and mechanical properties of natural fibre reinforced polypropylene. Compos Sci Technol 2009; 69: 1847-1853.

60. Oksman K, Skrifvars M and Selin JF. Natural fibres as reinforcement in polylactic acid (PLA) composites. Compos Sci Technol 2003; 63: 1317-1324.

61. Angelov I, Wiedmer S, Evstatiev M, et al. Pultrusion of a flax/polypropylene yarn. Compos Part A-Appl S 2007; 38: 1431-1438.

62. Oksman K. High quality flax fibre composites manufactured by the resin transfer moulding process. J Reinf Plast Comp 2001; 20: 621-627.

63. Baley C, Le Duigou A, Bourmaud A and Davies P. Influence of drying on the mechanical behaviour of flax fibres and their unidirectional composites. Compos Part A-Appl S 2012; 43: 1226-1233.

64. Fuentes C, Ting K, Dupont-Gillain C, et al. Effect of humidity during manufacturing on the interfacial strength of non-pre-dried flax fibre/unsaturated polyester composites. Compos Part A-Appl S 2016; 84: 209-215.

65. Newman RH. Auto-accelerative water damage in an epoxy composite reinforced with plain-weave flax fabric. Compos Part A-Appl S 2009; 40: 1615-1620.

66. Azwa ZN, Yousif BF, Manalo AC and Karunasena W. A review on the degradability of polymeric composites based on natural fibres. Mater Design 2013; 47: 424-442.

67. Assarar M, Scida D, El Mahi A, et al. Influence of water ageing on mechanical properties and damage events of two reinforced composite materials: Flax-fibres and glass-fibres. Mater Design 2011; 32: 788-795. 
68. Cheour K, Assarar M, Scida D, et al. Effect of water ageing on the mechanical and damping properties of flax-fibre reinforced composite materials. Compos Struct 2016; 152: 259-266.

69. Chilali A, Zouari W, Assarar M, et al. Effect of water ageing on the load-unload cyclic behaviour of flax fibre-reinforced thermoplastic and thermosetting composites. Compos Struct 2018; 183: 309-319.

70. Dhakal HN, Zhang ZY, Bennett N, et al. Effects of water immersion ageing on the mechanical properties of flax and jute fibre biocomposites evaluated by nanoindentation and flexural testing. J Compos Mater 2014; 48: 1399-1406.

71. Berges M, Leger R, Placet V, et al. Influence of moisture uptake on the static, cyclic and dynamic behaviour of unidirectional flax fibre-reinforced epoxy laminates. Compos Part A-Appl S 2016; 88: 165-177.

72. Scida D, Assarar M, Poilane C and Ayad R. Influence of hygrothermal ageing on the damage mechanisms of flax-fibre reinforced epoxy composite. Compos Part B-Eng 2013; 48: 51-58.

73. Saidane E, Scida D, Assarar M and Ayad R. Assessment of 3D moisture diffusion parameters on flax/epoxy composites. Compos Part A-Appl S 2016; 80:53-60.

74. Celino A, Freour S, Jacquemin F and Casari P. Characterization and modeling of the moisture diffusion behavior of natural fibers. J Appl Polym Sci 2013; 130: 297-306.

75. Munoz E and Garcia-Manrique JA. Water Absorption Behaviour and Its Effect on the Mechanical Properties of Flax Fibre Reinforced Bioepoxy Composites. Int J Polym Sci 2015; 2015: 1-10.

76. Arbelaiz A, Fernandez B, Ramos JA, et al. Mechanical properties of short flax fibre bundle/polypropylene composites: Influence of matrix/fibre modification, fibre content, water uptake and recycling. Compos Sci Technol 2005; 65: 1582-1592.

77. Athijayamani A, Thiruchitrambalam M, Natarajan U and Pazhanivel B. Effect of moisture absorption on the mechanical properties of randomly oriented natural fibers/polyester hybrid composite. Mat Sci Eng A-Struct 2009; 517: 344-353.

78. Le Duigou A, Davies P and Baley C. Seawater ageing of flax/poly(lactic acid) biocomposites. Polym Degrad Stabil 2009; 94: 1151-1162.

79. Le Duigou A, Bourmaud A, Balnois E, et al. Improving the interfacial properties between flax fibres and PLLA by a water fibre treatment and drying cycle. Ind Crop Prod 2012; 39: 31-39.

80. Stamboulis A, Baillie $\mathrm{C}$ and Schulz E. Interfacial characterisation of flax fibrethermoplastic polymer composites by the pull-out test. Angew Makromol Chem 1999; 272: 117-120.

81. Saheb DN and Jog JP. Natural fiber polymer composites: A review. Adv Polym Tech 1999; 18: 351-363.

82. Suddell BC and Evans WJ. Natural fiber composites in automotive applications. In: Mohanty AK, Misra M and Drzal LT (Eds.) Natural fibers, biopolymers, and biocomposites, Ch. 7. Boca Raton: CRC Press, 2005.

83. George M, Chae M and Bressler DC. Composite materials with bast fibres: Structural, technical, and environmental properties. Prog Mater Sci 2016; 83: 1-23.

84. Yan LB. Plain concrete cylinders and beams externally strengthened with natural flax fabric reinforced epoxy composites. Mater Struct 2016; 49: 2083-2095. 


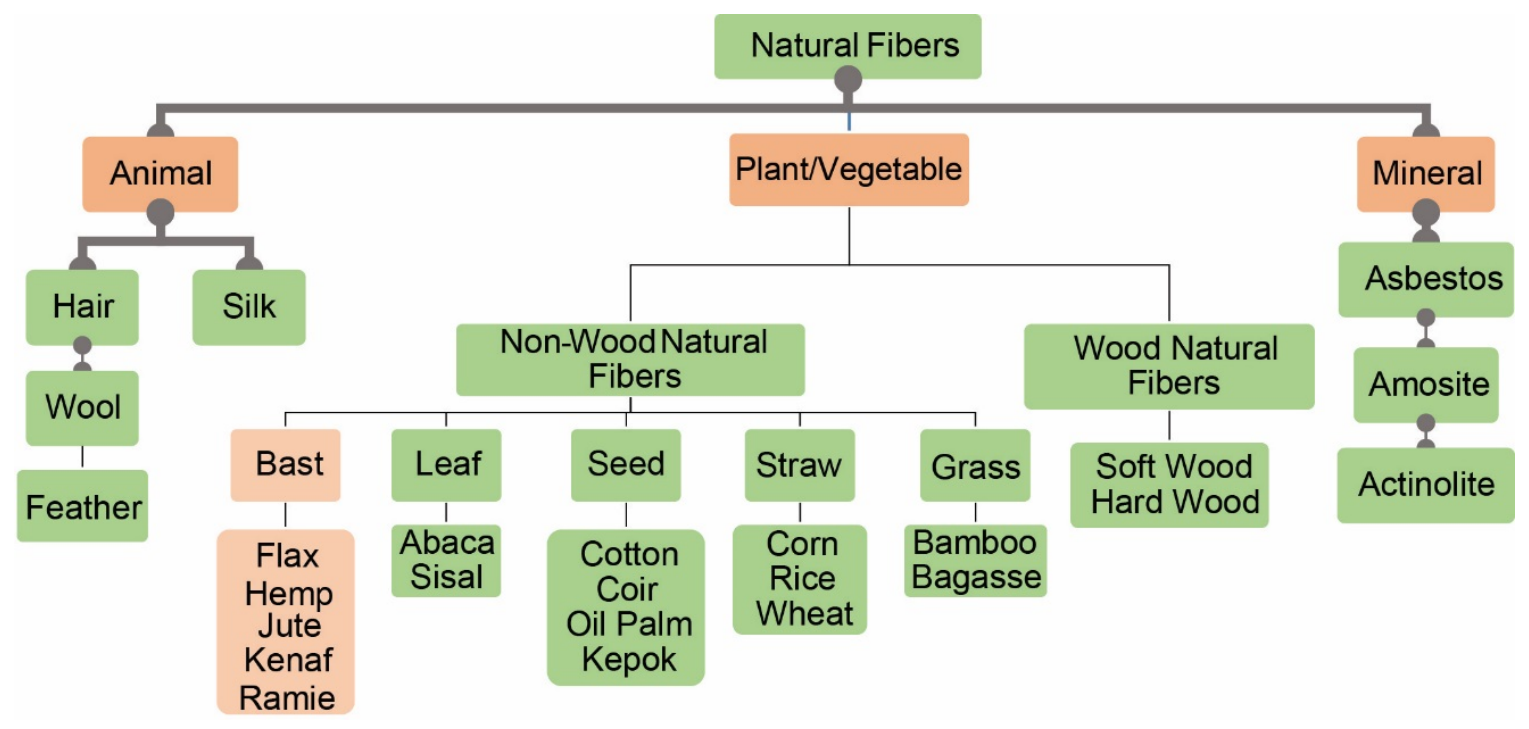

Figure 1. Classification of natural fibers. 


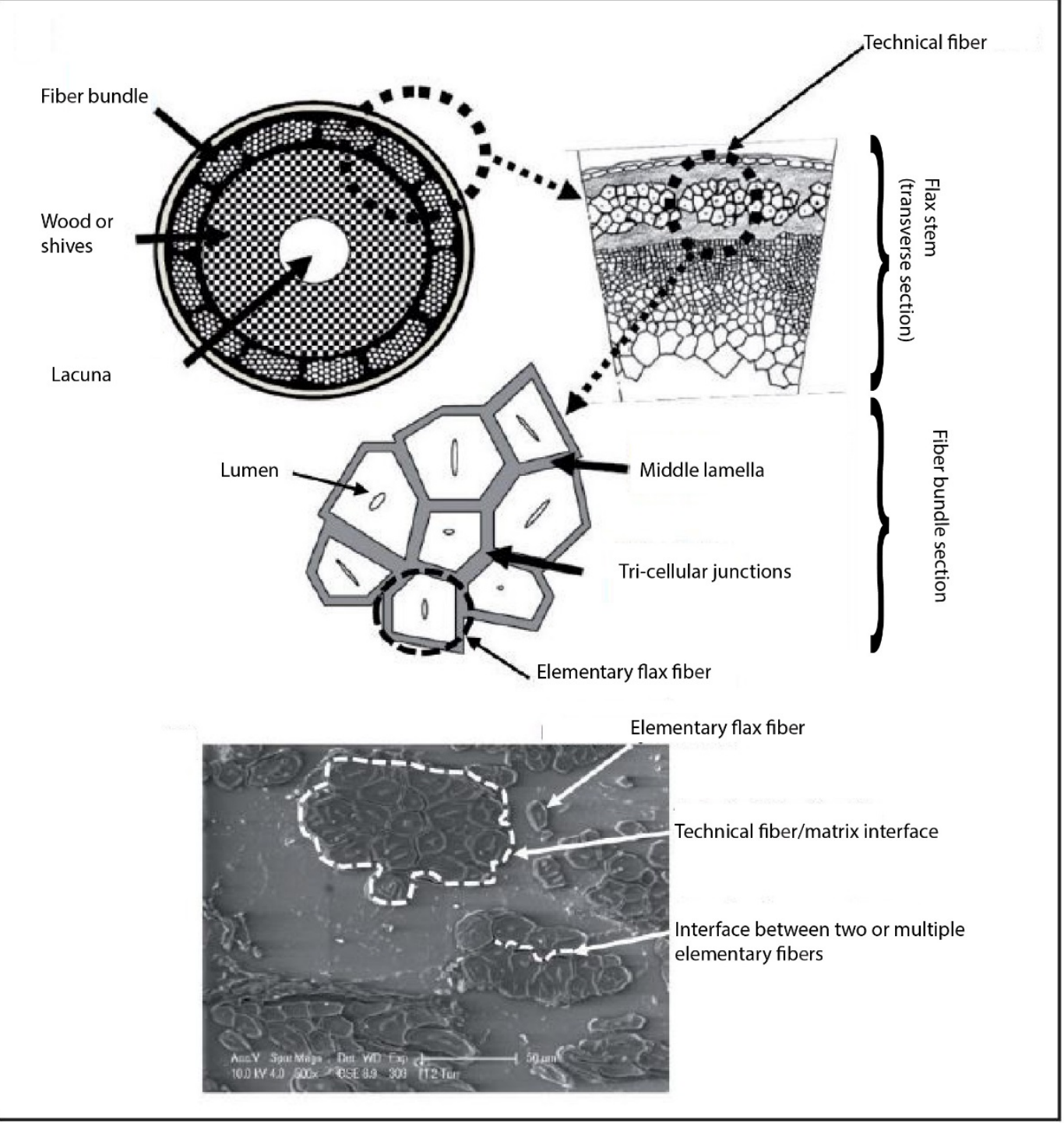

Figure 2. Structure of the flax fiber: (a) cross section of flax plant stem and position of the bundles of elementary fibers and technical fibers after extraction, (b) SEM image of a technical fiber with its constituting elementary fibers (reproduced with permission from ${ }^{24}$ ). 


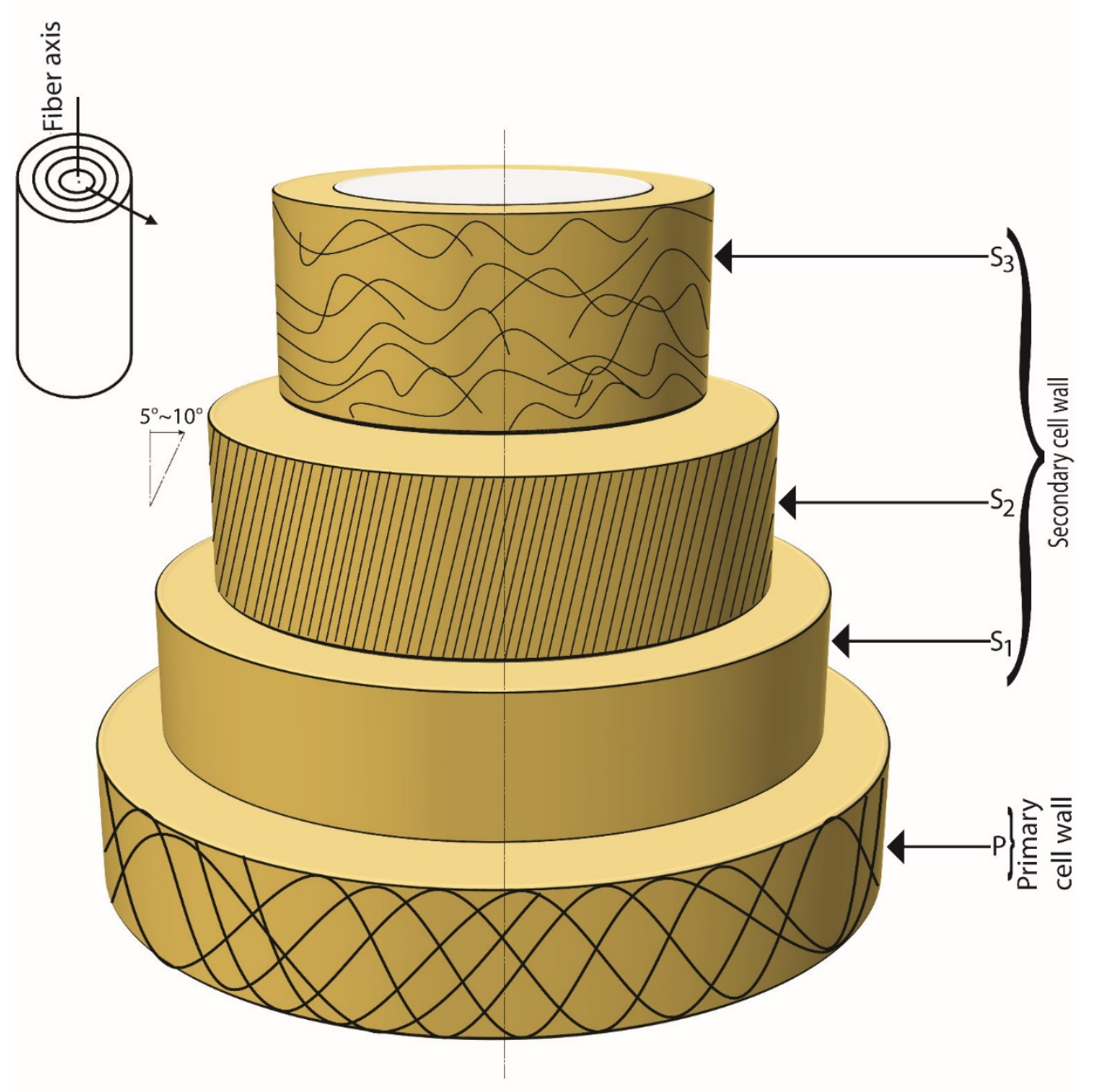

Figure 3. An elementary fiber structure (reproduced with permission from ${ }^{29}$ ). 


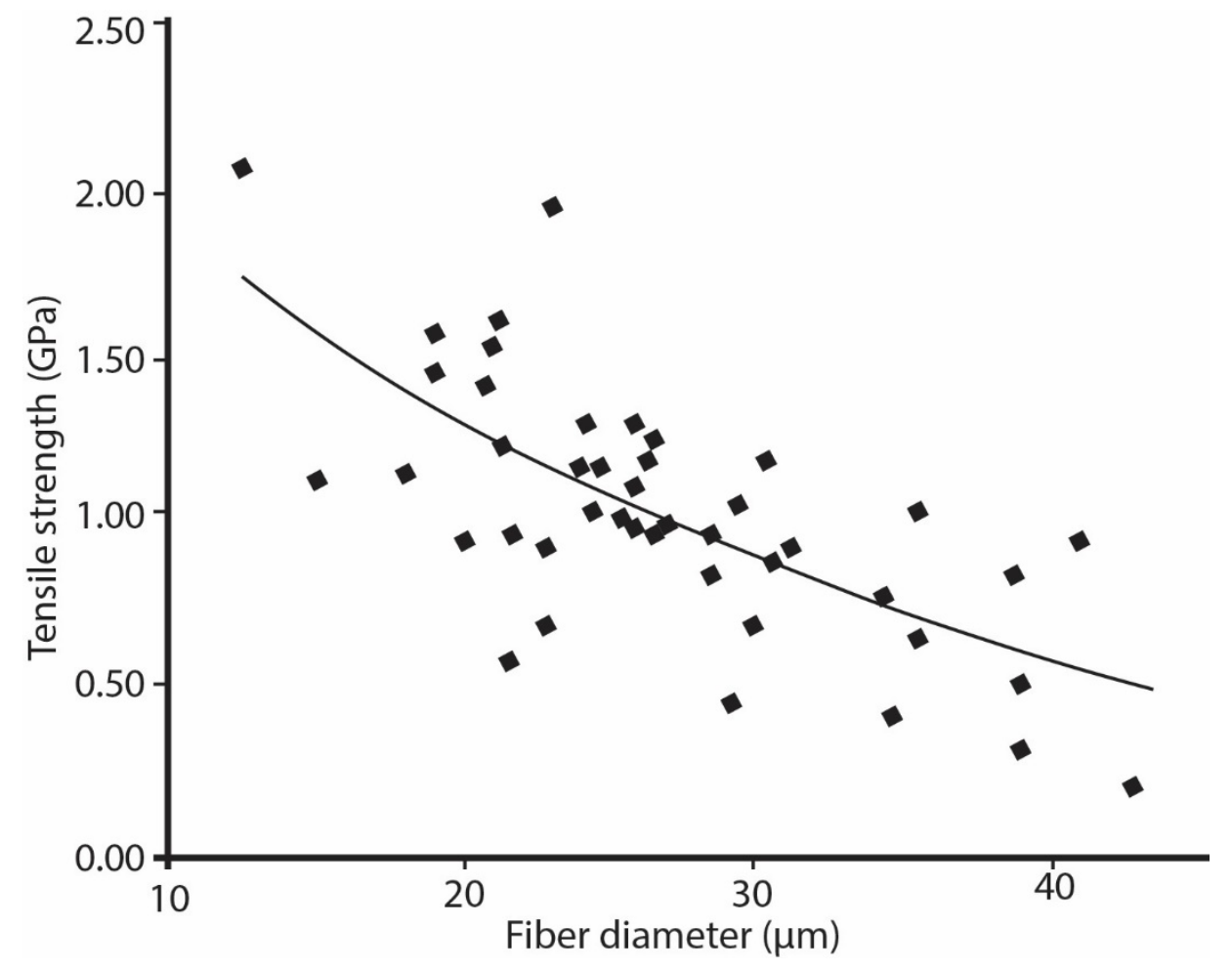

Figure 4. Effect of fiber diameter on fiber strength (reproduced with permission from $^{40}$ ). 


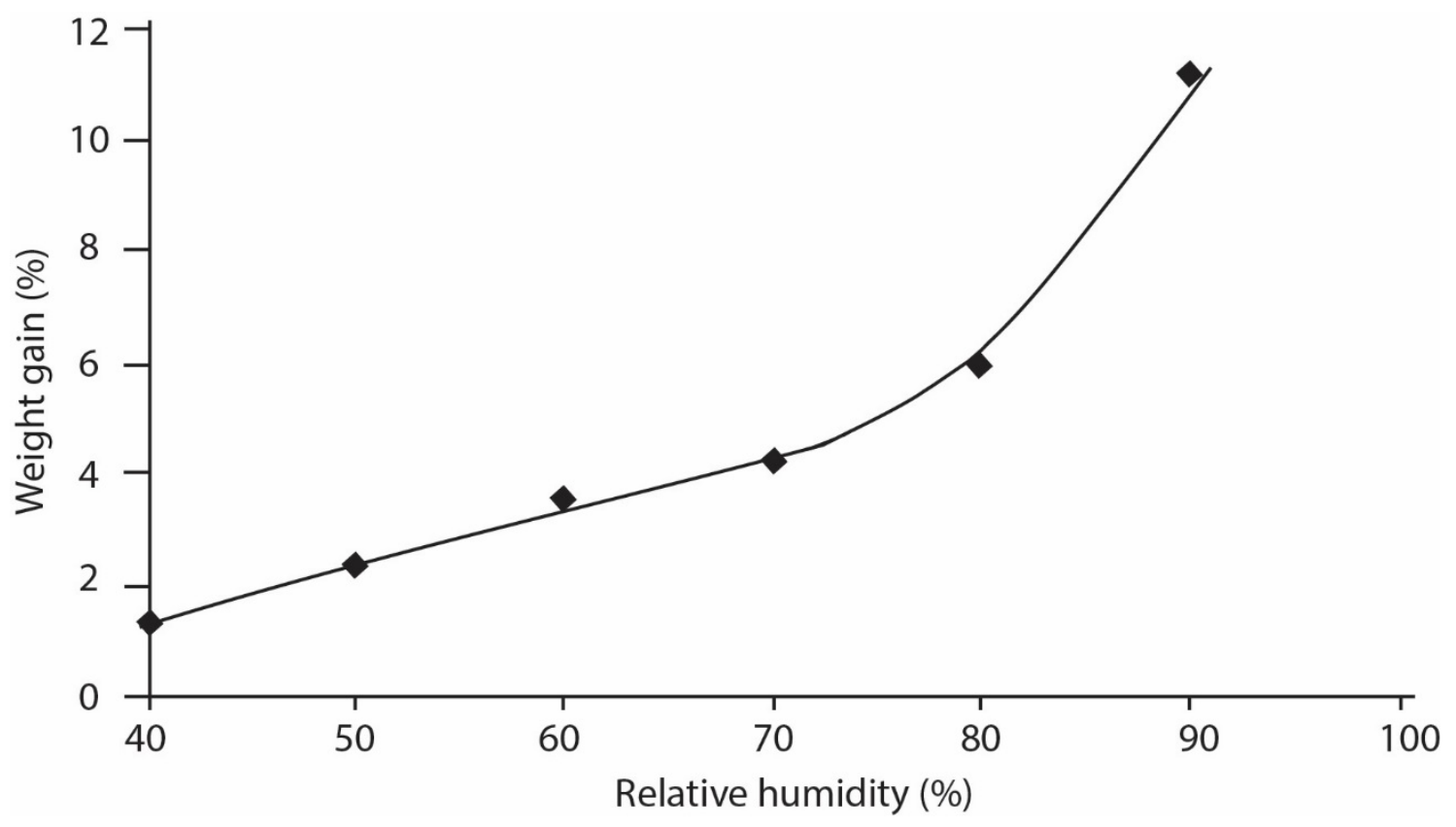

Figure 5. Equilibrium moisture absorption of flax sliver at different $\mathrm{RH}$ (reproduced with permission from ${ }^{43}$ ). 


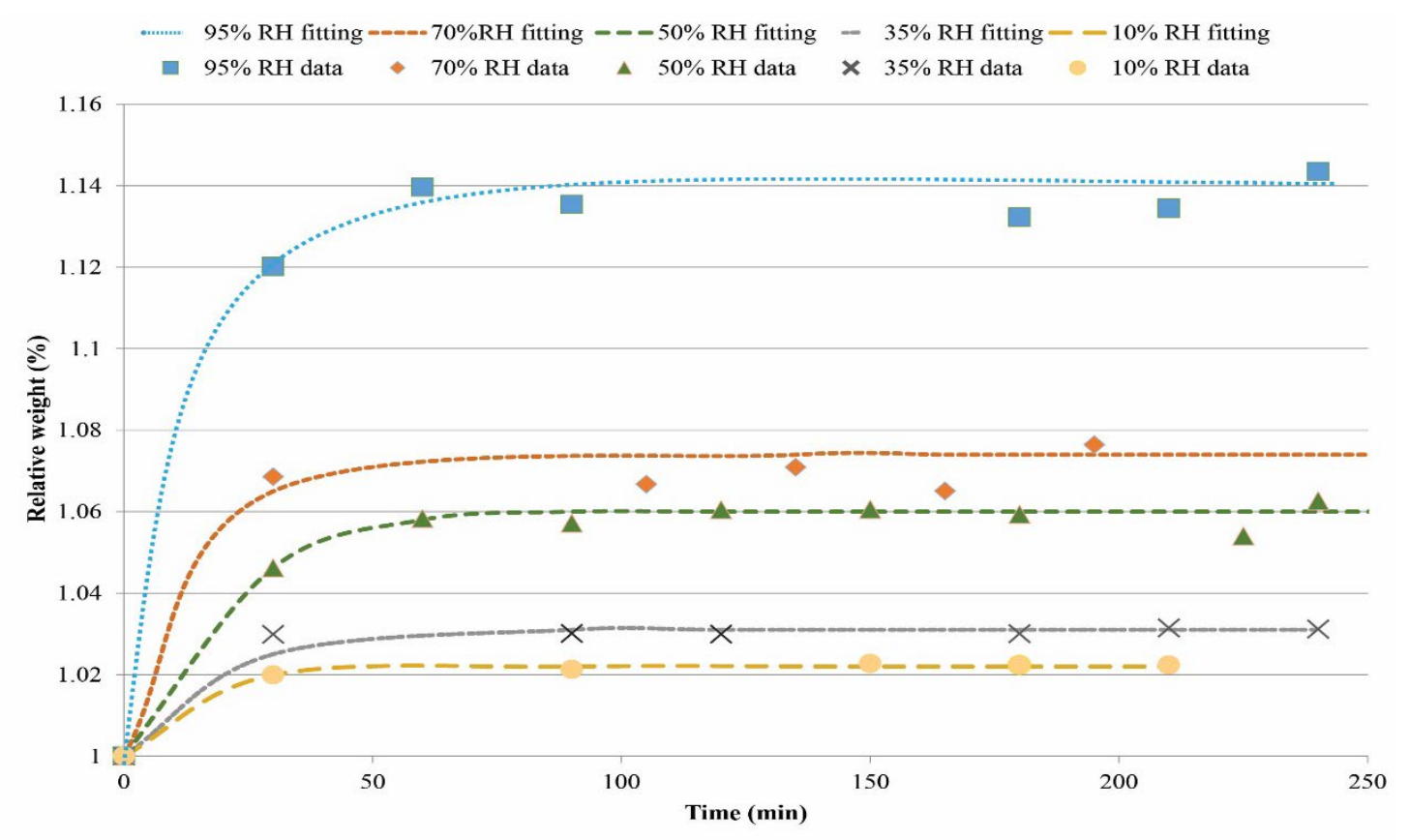

Figure 6. Moisture absorption kinetics of flax fibers at different $\mathrm{RH}$ (reproduced with permission from ${ }^{44}$ ). 


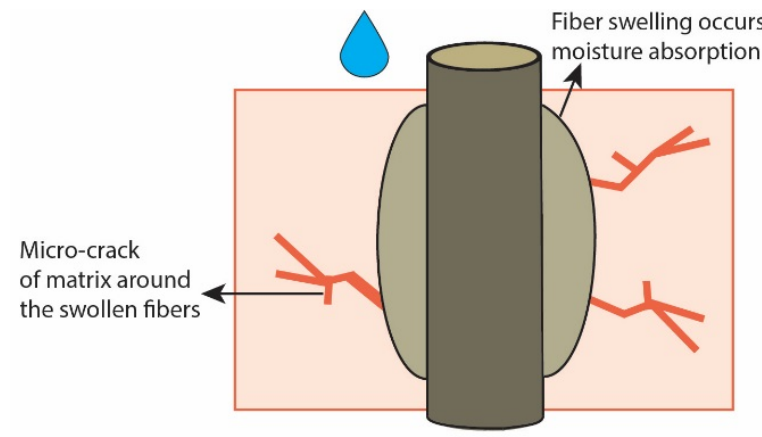

(a)

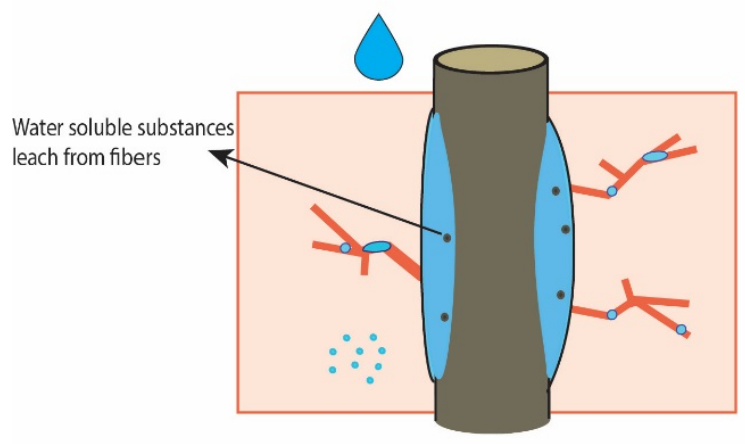

(c)

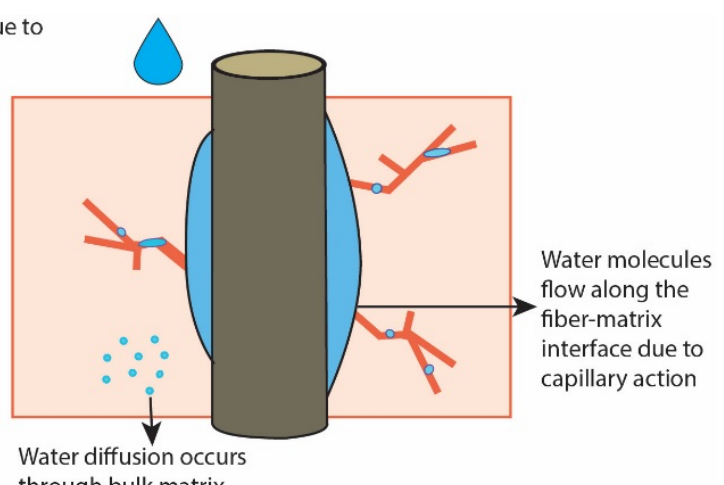

(b)

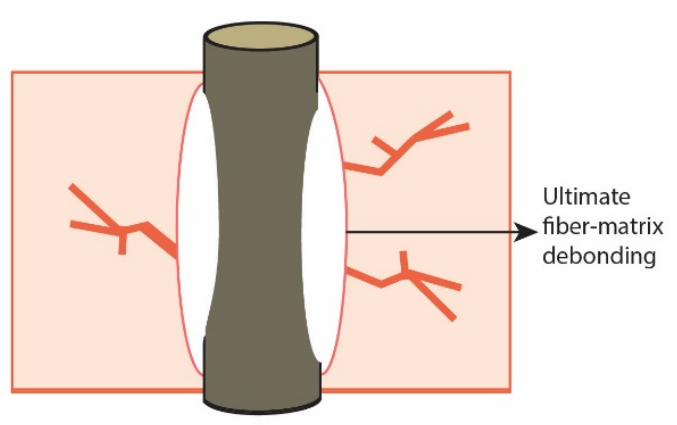

(d)

Figure 7. Debonding process in fiber/matrix interface with water (reproduced with permission from ${ }^{66}$ ). 


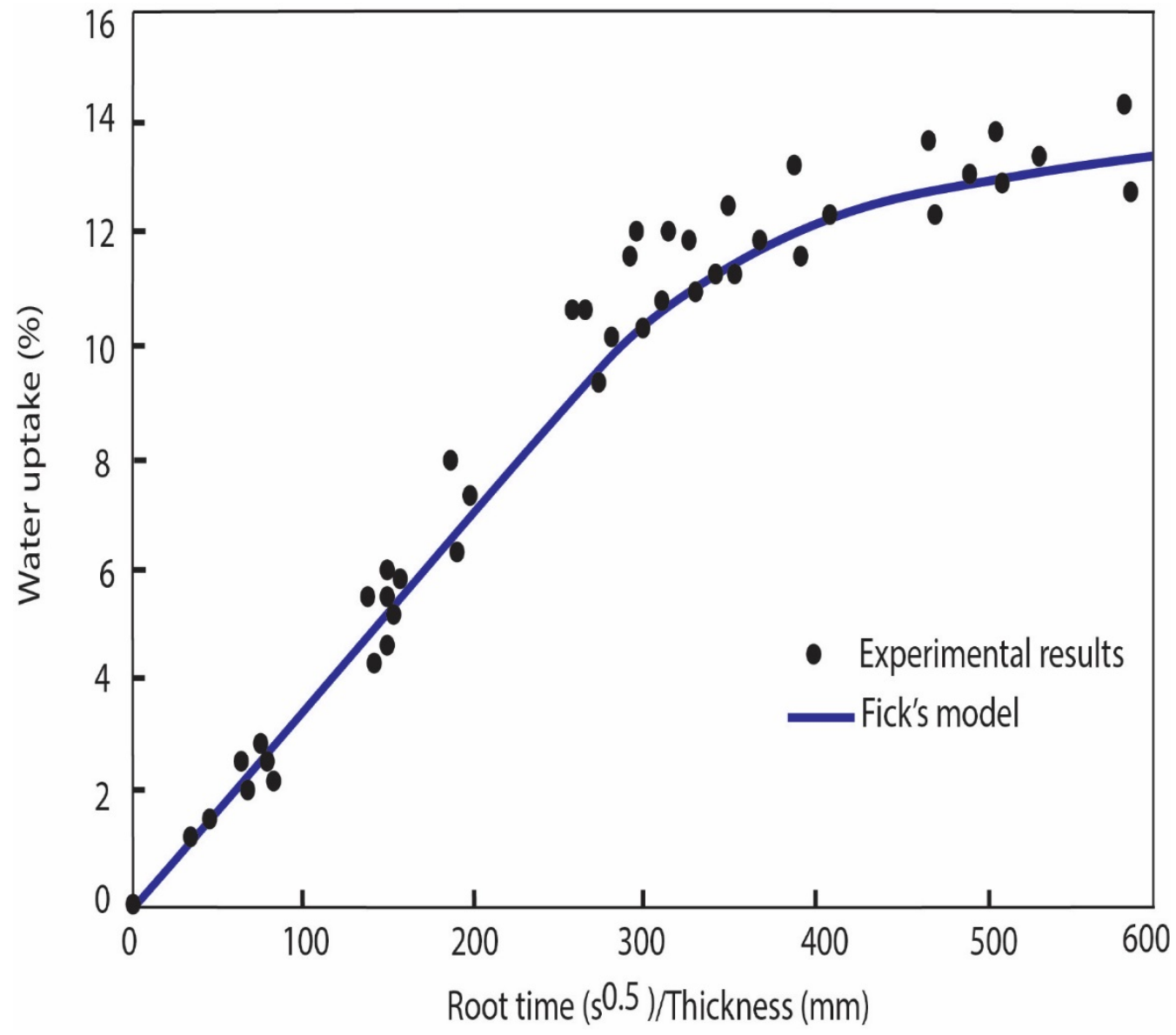

Figure 8. Water absorption pattern of flax-epoxy composites (reproduced with permission from ${ }^{67}$ ). 


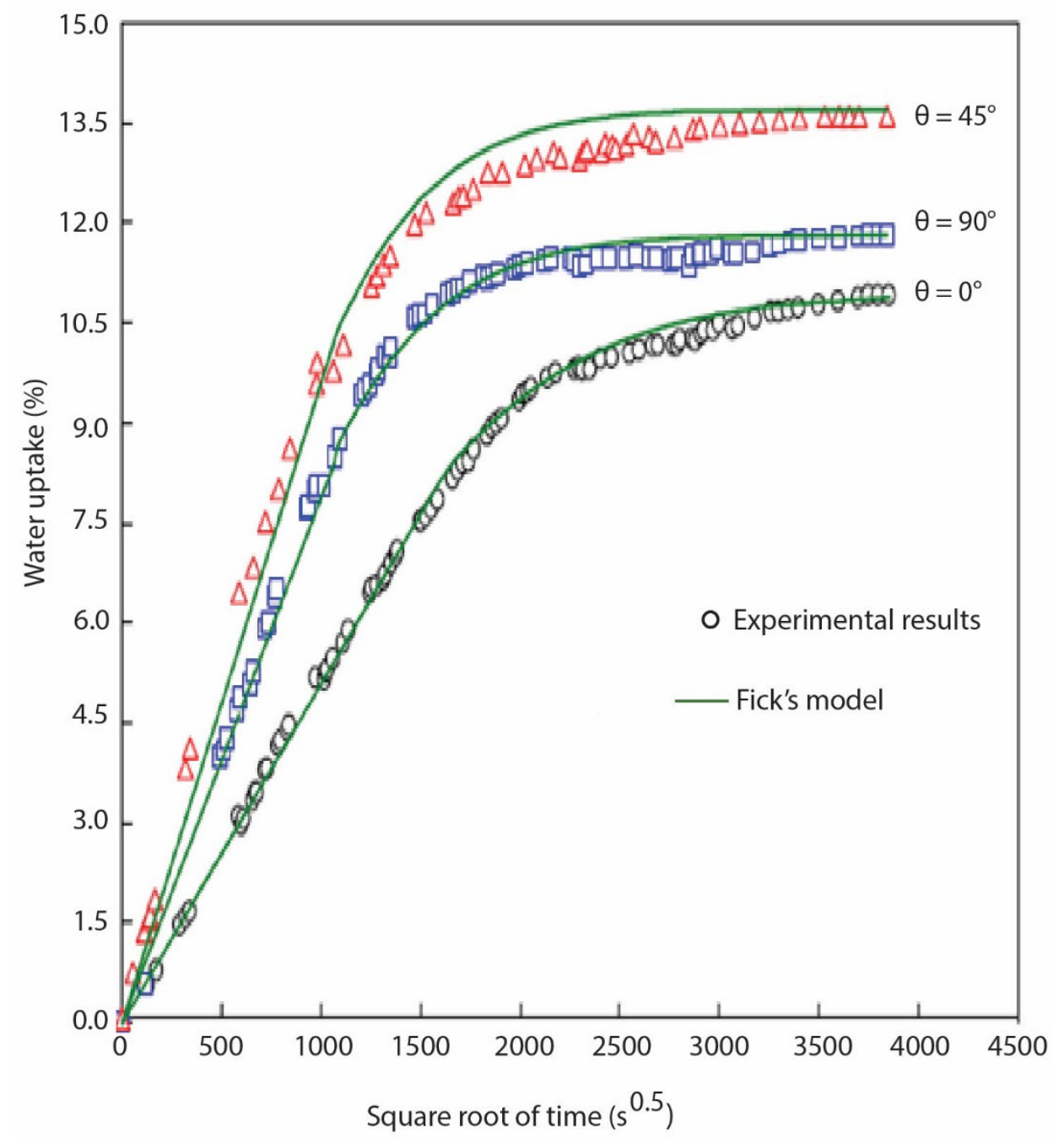

Figure 9. Moisture absorption of flax composites with different fiber orientation (reproduced with permission from ${ }^{68}$ ). 


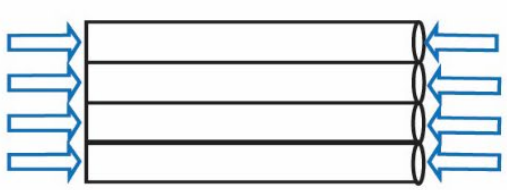

(a)

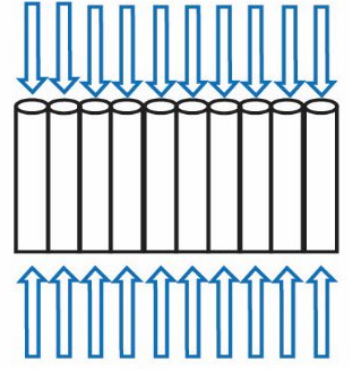

(b)

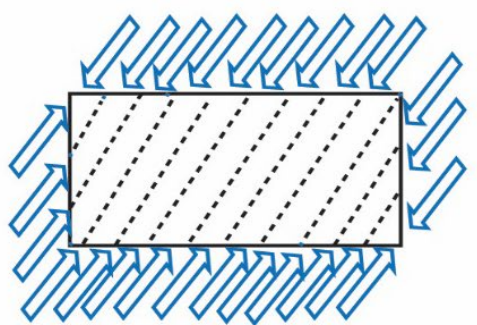

(c)

Figure 10. Water diffusion of flax composites in different fiber orientation $\left(a=0^{\circ}\right.$, $\left.b=90^{\circ}, c=45^{\circ}\right)\left(\right.$ reproduced with permission from $\left.{ }^{68}\right)$. 


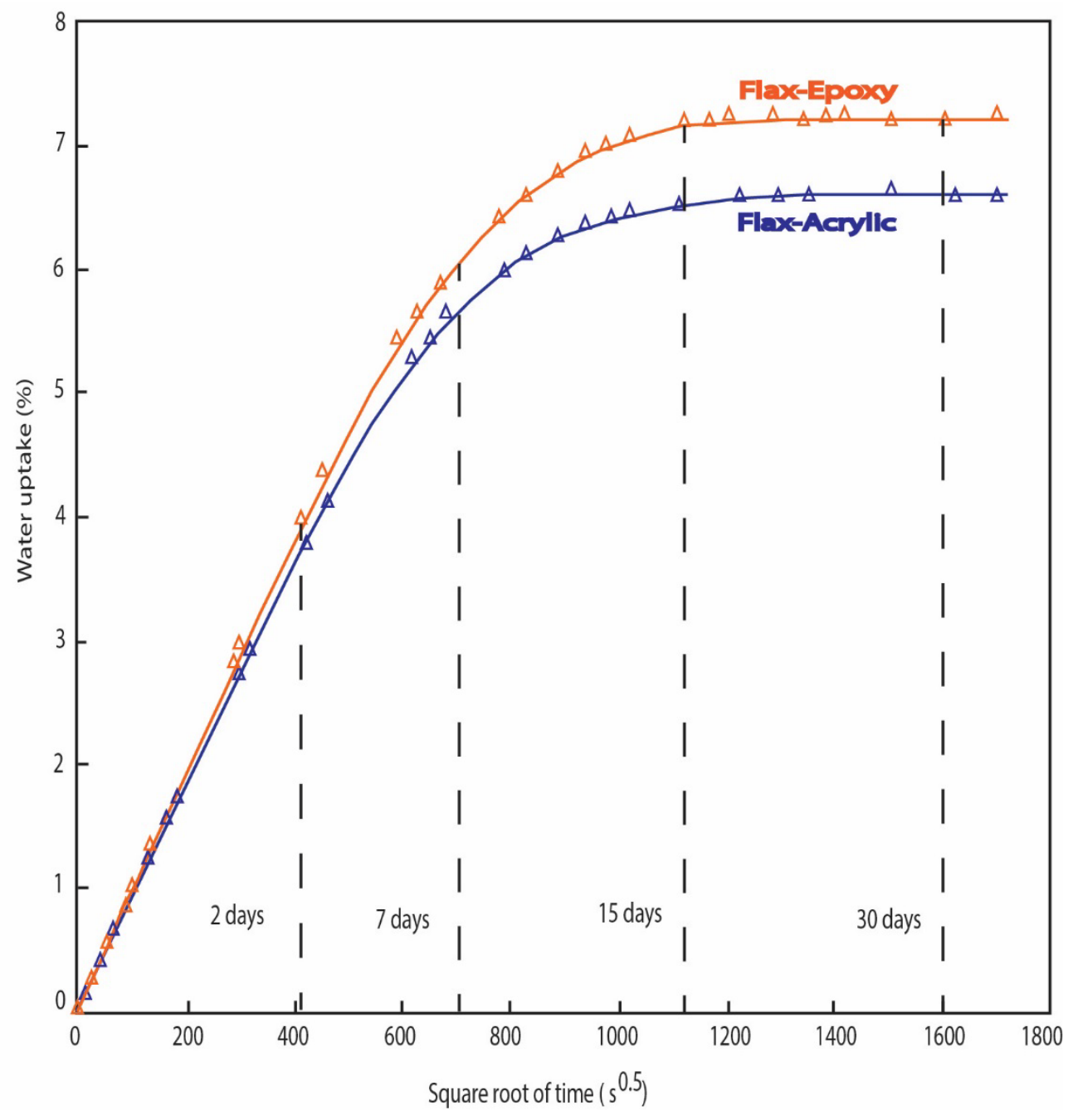

Figure 11. Water absorption of flax/epoxy and flax/acrylic composites (reproduced with permission from ${ }^{69}$ ) 
Table 1. Bast fibers: compositions, physical and mechanical properties. ${ }^{1,31-33}$

\begin{tabular}{|c|c|c|c|c|c|c|c|c|c|}
\hline $\begin{array}{l}\text { Bast } \\
\text { fibers }\end{array}$ & Cellulose & Hemicellulose & Lignin & Pectin & Wax & $\begin{array}{l}\text { Density } \\
\text { (gm/cc) }\end{array}$ & $\begin{array}{c}\text { Young's } \\
\text { modulus } \\
(\mathrm{GPa})\end{array}$ & $\begin{array}{c}\text { Tensile } \\
\text { strength } \\
\text { (MPa) }\end{array}$ & $\begin{array}{l}\text { Elongation } \\
\text { at break } \\
(\%)\end{array}$ \\
\hline \multicolumn{10}{|c|}{$(\%)$} \\
\hline Flax & $60-81$ & $14-20.6$ & $2-3$ & $1.8-5$ & 1.7 & 1.5 & 27.6 & $345-1500$ & $2.7-3.2$ \\
\hline Hemp & $70-92$ & $17.9-22.4$ & $3-5.7$ & 0.9 & 0.8 & $1.4-1.5$ & $17-70$ & $368-800$ & $1.6-4$ \\
\hline Jute & $51-84$ & $12-20.4$ & $5-13$ & 0.2 & 0.5 & $1.3-1.4$ & $10-30$ & $393-773$ & $1.2-1.5$ \\
\hline Kenaf & $31-57$ & $13.6-21$ & $5.9-19$ & 2 & - & 1.2 & $14-53$ & $240-930$ & 1.6 \\
\hline Ramie & 68.6-76.2 & $13-16.7$ & $0.6-1$ & $1.9-2$ & - & $1.5-1.56$ & $27-128$ & $400-1000$ & $1.2-3.8$ \\
\hline Banana & $60-65$ & $6-19$ & $5-10$ & $3-5$ & - & $1.3-1.35$ & $27-32$ & $529-914$ & $1-3$ \\
\hline
\end{tabular}


Table 2. Liquid composite molding processes. ${ }^{58}$

\begin{tabular}{lllll}
\hline Methods & Type of mold used & $\begin{array}{l}\text { Volume of } \\
\text { production }\end{array}$ & $\begin{array}{l}\text { Part } \\
\text { complexity }\end{array}$ & Part size \\
\hline $\begin{array}{l}\text { Resin transfer molding } \\
\text { (RTM) }\end{array}$ & $\begin{array}{l}\text { Rigid mold (steel or } \\
\text { aluminium) }\end{array}$ & High & High & Small-medium \\
$\begin{array}{l}\text { Light resin transfer } \\
\text { molding (LRTM) }\end{array}$ & $\begin{array}{l}\text { Rigid mold (glass fibre } \\
\text { reinforced composites) }\end{array}$ & Low-Medium & Medium & Small-medium \\
Vacuum infusion (VI) & $\begin{array}{l}\text { Rigid lower mold-flexible } \\
\text { sheet (vacuum bag, } \\
\text { plastic sheet, silicone or } \\
\text { rubber membrane) }\end{array}$ & Low & Medium & Medium-large \\
$\begin{array}{l}\text { Injection compression } \\
\text { molding (ICM) }\end{array}$ & $\begin{array}{l}\text { Rigid mold (steel or } \\
\text { aluminium) }\end{array}$ & Medium-high & Medium & Small-medium \\
\hline
\end{tabular}


Table 3. Diffusion coefficients of flax fiber composites according to literature.

\begin{tabular}{|c|c|c|c|c|}
\hline Fiber conditions and humidity & $\begin{array}{l}\text { Matrix } \\
\text { used }\end{array}$ & $\begin{array}{l}\text { Diffusion coefficient, } \\
\mathrm{D}\left(\mathrm{cm}^{2} / \mathrm{s}\right)\end{array}$ & $\begin{array}{l}\text { Manufacturing methods and } \\
\text { other conditions }\end{array}$ & Reference \\
\hline \multirow{2}{*}{$\begin{array}{l}\text { UD and twill fibers } \\
\text { at } 55^{\circ} \mathrm{C} \text { and } 75 \% \mathrm{RH}\end{array}$} & \multirow[t]{2}{*}{ UP } & $0.00104 \times 10^{-3} \pm 0.02$ & \multirow{2}{*}{$\begin{array}{l}\text { Hand lay-up, } 8.89 \% \text { water } \\
\text { uptake for UD flax composites } \\
\text { and } 10.24 \% \text { uptake for twill } \\
\text { flax composites }\end{array}$} & \multirow[t]{2}{*}{73} \\
\hline & & $0.00287 \times 10^{-3} \pm 0.08$ & & \\
\hline Green flax & PP & $1.3 \times 10^{-2}$ & \multirow{3}{*}{$\begin{array}{l}\text { Moisture uptake reduced by } \\
30 \% \text { in treated flax composites } \\
\text { (duration } 14 \text { days) }\end{array}$} & \multirow[t]{3}{*}{45} \\
\hline Treated flax & \multirow{3}{*}{$\begin{array}{l}\text { PP } \\
\text { MAPP }\end{array}$} & $7.8 \times 10^{-3}$ & & \\
\hline Treated flax & & $5.0 \times 10^{-3}$ & & \\
\hline Flax at $23^{\circ} \mathrm{C}, 80 \% \mathrm{RH}$ & & $0.002 \times 10^{-3}$ & Extrusion & 74 \\
\hline $\begin{array}{l}\text { Flax at } 25^{\circ} \mathrm{C} \text {, maximum } \\
\text { immersion } 40 \text { days }\end{array}$ & Bio epoxy & 37.1 & $\begin{array}{l}\text { Hand lay-up, } \\
\text { Equilibrium moisture content, } \\
9.61 \%\end{array}$ & 70 \\
\hline \multirow{3}{*}{$\begin{array}{l}\text { Flax at three orientations }\left(0^{\circ} \text {, }\right. \\
\left.45^{\circ}, 90^{\circ}\right) \text {, immersion at room } \\
\text { temperature }\end{array}$} & \multirow[t]{3}{*}{ Epoxy } & $6.67 \times 10^{-9}$ for $0^{\circ}$ & \multirow{3}{*}{$\begin{array}{l}\text { Press platen process, } \\
\text { Maximum moisture uptake } \\
13.70 \% \text { by } 45^{\circ} \text { fiber orientation }\end{array}$} & \multirow[t]{3}{*}{68} \\
\hline & & $12.45 \times 10^{-9}$ for $45^{\circ}$ & & \\
\hline & & $14.19 \times 10^{-9}$ for $90^{\circ}$ & & \\
\hline \multirow{2}{*}{$\begin{array}{l}0^{\circ} / 90^{\circ} \text { flax at } 40 \text { and } 55 \mathrm{wt} \% \text {, } \\
\text { immersion at room } \\
\text { temperature, } 32 \text { days } \\
\text { immersion test }\end{array}$} & \multirow[t]{2}{*}{ Bio-epoxy } & $1.63 \times 10^{-8}$ for $40 \%$ & \multirow{2}{*}{$\begin{array}{l}\text { RTM, Saturation water } \\
\text { absorption } 8.71 \% \text { and } 6.23 \% \\
\text { by } 55 \% \text { and } 40 \% \text { fiber volume } \\
\text { respectively }\end{array}$} & \multirow[t]{2}{*}{75} \\
\hline & & $2.32 \times 10^{-8}$ for $55 \%$ & & \\
\hline \multirow{2}{*}{$\begin{array}{l}\text { Twill flax, immersion at room } \\
\text { temperature }\end{array}$} & Acrylic & $7.7 \times 10^{-9} \pm 0.03$ & \multirow{2}{*}{$\begin{array}{l}\text { Vacuum infusion, moisture at } \\
\text { equilibrium, } 6.6 \% \text { for flax- } \\
\text { acrylic and } 7.31 \% \text { for flax- } \\
\text { epoxy composites }\end{array}$} & \multirow[t]{2}{*}{69} \\
\hline & Epoxy & $8.1 \times 10^{-9} \pm 0.04$ & & \\
\hline \multirow{2}{*}{$\begin{array}{l}\text { Flax fiber bundles, immersion } \\
\text { test at room temperature ( } 212 \\
\text { days), } 40 \% \text { fiber volume }\end{array}$} & PP & $2.23 \times 10^{9}$ & \multirow{2}{*}{$\begin{array}{l}\text { Compounding, saturated } \\
\text { moisture content, } 9.09 \% \text { for } \\
\text { flax-PP and } 8.53 \% \text { for flax- } \\
\text { MAPP composites }\end{array}$} & \multirow[t]{2}{*}{76} \\
\hline & MAPP & $0.92 \times 10^{9}$ & & \\
\hline
\end{tabular}

